OPEN ACCESS

Edited by:

Shashank Keshavmurthy, Biodiversity Research Center,

Academia Sinica, Taiwan

Reviewed by:

Nicola Browne,

Curtin University, Australia

Kyle Morgan

Nanyang Technological

University, Singapore

*Correspondence:

Ross Jones

r.jones@aims.gov.au

Specialty section: This article was submitted to

Coral Reef Research,

a section of the journal

Frontiers in Marine Science

Received: 18 June 2021

Accepted: 31 August 2021

Published: 18 November 2021

Citation:

Jones $R$, Pineda M-C, Luter HM, Fisher $R$, Francis $D$, Klonowski $W$ and

Slivkoff M (2021) Underwater Light

Characteristics of Turbid Coral Reefs of the Inner Central Great Barrier Reef.

Front. Mar. Sci. 8:727206.

doi: 10.3389/fmars.2021.727206

\section{Underwater Light Characteristics of Turbid Coral Reefs of the Inner Central Great Barrier Reef}

\author{
Ross Jones ${ }^{1 *}$, Mari-Carmen Pineda ${ }^{1}$, Heidi M. Luter ${ }^{1}$, Rebecca Fisher ${ }^{1}$, David Francis ${ }^{2}$, \\ Wojciech Klonowski ${ }^{3}$ and Matthew Slivkoff ${ }^{3}$
}

${ }^{1}$ Australian Institute of Marine Science, Perth, WA, Australia, ${ }^{2}$ School of Life and Environmental Sciences, Deakin University, Warrnambool, VIC, Australia, ${ }^{3}$ In-situ Marine Optics, Perth, WA, Australia

Hyper-spectral and multi-spectral light sensors were used to examine the effects of elevated suspended sediment concentration (SSC) on the quantity and quality (spectral changes) of underwater downwelling irradiance in the turbid-zone coral reef communities of the inner, central Great Barrier Reef (GBR). Under elevated SSCs the shorter blue wavelengths were preferentially attenuated which together with attenuation of longer red wavelengths by pure water shifted the peak in the underwater irradiance spectrum $\sim 100 \mathrm{~nm}$ to the less photosynthetically useful green-yellow waveband (peaking at $\sim 575 \mathrm{~nm}$ ). The spectral changes were attributed to mineral and detrital content of the terrestrially-derived coastal sediments as opposed to chromophoric (coloured) dissolved organic matter (CDOM). A simple blue to green (B/G, $\lambda 455: 555 \mathrm{~nm})$ ratio was shown to be useful in detecting sediment (turbidity) related decreases in underwater light as opposed to those associated with clouds which acted as neutral density filters. From a series of vertical profiles through turbid water, a simple, multiple component empirical optical model was developed that could accurately predict the light reduction and associated spectral changes as a function of SSC and water depth for a turbid-zone coral reef community of the inner GBR. The relationship was used to assess the response of a light sensitive coral, Pocillopora verrucosa in a 28-d exposure laboratory-based exposure study to a daily light integral of 1 or $6 \mathrm{~mol}$ quanta $\mathrm{m}^{2}$. PAR with either a broad spectrum or a green-yellow shifted spectrum. Light reduction resulted in a loss of the algal symbionts (zooxanthellae) of the corals (bleaching) and significant reduction in growth and lipid content. The 6 mol quanta $\mathrm{m}^{2} \mathrm{~d}^{-1}$ PAR treatment with a green-yellow spectrum also resulted in a reduction in the algal density, Chl a content per $\mathrm{cm}^{2}$, lipids and growth compared to the same PAR daily light integral under a broad spectrum. Turbid zone coral reef communities are naturally light limited and given the frequency of sediment resuspension events that occur, spectral shifts are a common and previously unrecognised circumstance. Dedicated underwater light monitoring programs and further assessment of the spectral shifts by suspended sediments are essential for contextualising and further understanding the risk of enhanced sediment run-off to the inshore turbid water communities.

Keywords: turbidity, coral reef, suspended sediment, downwelling irradiance, spectral changes 


\section{INTRODUCTION}

Light is essential for reef-building corals on account of their mutualistic symbiosis with photosynthetic symbiotic dinoflagellates (Falkowski et al., 1990; Muscatine, 1990; Lesser, 2004; Roth, 2014). Although corals are capable of feeding heterotrophically (Houlbrèque and Ferrier-Pagès, 2009), photosynthetic energy conversion provides much more energy influencing many aspects of their physiology and ecology (Falkowski et al., 1990; Yentsch et al., 2002; Gattuso et al., 2006; Dubinsky and Falkowski, 2011; Roth, 2014). The exponential decrease in light with water depth contributes significantly to changes in species composition and abundance and morphology (Goreau, 1959; Goreau and Wells, 1967; Dustan, 1982; Huston, 1985; Schuhmacher and Zibrowius, 1985; Wyman et al., 1987; Kramer et al., 2020). Latitudinal decreases in light availability has also been suggested a possible critical limiting factor for corals (Kleypas et al., 1999; Muir et al., 2015). The attenuation of light from increased water cloudiness (turbidity) from enhanced terrestrial runoff has been suggested as a threat to coastal marine ecosystems (ISRS, 2004; GBRMPA, 2020). Yet despite its significance, Yentsch et al. (2002) and more recently Edmunds et al. (2018) and Hochberg et al. (2020) have questioned why light on reefs has not been critically examined to the same extent as for other environmental factors (e.g., temperature, salinity, disease, etc.).

Solar radiation penetration to the seabed is determined by season, solar elevation, sea state, water depth and especially the optical properties of the water column (Kirk, 2010). Components of the water that can modify the underwater light field fall within three broad categories including phytoplankton, chromophoric (coloured) dissolved organic matter (CDOM) and non-algal particulates (NAP) (Mobley, 1994; Kirk, 2010). Together with the spectral attenuation of the pure seawater itself the relative contributions of the individual components determine the intensity and spectral quality of the light reaching the seabed (Prieur and Sathyendranath, 1981; Babin et al., 2003b; Kirk, 2010).

Over the visible/photosynthetic part of the spectrum (400$700 \mathrm{~nm}$ ) water absorbs strongly in the longer red wavelengths (Smith and Baker, 1981; Kirk, 2010). Phytoplankton absorb mostly in the shorter blue and blue green wavelengths (Prieur and Sathyendranath, 1981; Van Duin et al., 2001) and CDOM absorbs more strongly in the shorter blue wavelengths and into the ultraviolet (Bricaud et al., 1981; Hansell and Carlson, 2002; Shi et al., 2013). Non-algal particulates consisting of mineral sediments, non-living organic detritus such as faecal matter and degrading phytoplankton cells (Binding et al., 2008), produce a similar spectral signal to CDOM, absorbing in the shorter blue wavelength and decreasing steadily towards the longer red wavelengths (Kirk, 1985, 2010; Babin and Stramski, 2002, 2004; Bowers and Binding, 2006; Binding et al., 2008).

Most studies of light absorption and scattering have focused on Case-1 waters in the bipartite classification scheme of Morel and Prieur (1977). These waters are optically "simple" and include most open water, oceanic environments (Babin et al., 2003a) where the optical properties are largely determined by phytoplankton (represented by chlorophyll) alone (Smith and Baker, 1978; Morel, 1988; Mobley, 1994; Lee et al., 2007b; Morel et al., 2007). Case-1 waters typify the "traditional" perception of coral reefs as occurring in a "clear-water" or "blue water," nutrient-poor, oligotrophic environments (Potts and Jacobs, 2000). In Case- 1 waters the water column gradually narrows the spectrum with depth to one dominated by blue light. Since the initial work of Dustan (1982), many studies have now described this spectral change and examined and partitioned the biooptical properties in clear-water reefs (Dunne and Brown, 1996; Maritorena and Guillocheau, 1996; Lesser and Gorbunov, 2001; Lesser, 2004; Blondeau-Patissier et al., 2009; Lesser et al., 2009; Kuwahara et al., 2010; Mass et al., 2010; Dubinsky and Falkowski, 2011; Brandon et al., 2019; Kahng et al., 2019; Hochberg et al., 2020).

Case-2 waters are more optically complex because light absorption and scattering is influenced by suspended sediments (mineral NAPS) as well as CDOM and phytoplankton (Jerlov, 1976; Mobley, 1994; IOCCG, 2000; Babin et al., 2003a; Kirk, 2010). Case-2 waters are typically in coastal areas influenced by terrestrial run off and wind and wave induced resuspension of the shallow seabed with mineral NAPs often dominating the spectral signal (Duarte et al., 1998; Bowers and Binding, 2006; Binding et al., 2008). Corals reefs are commonly found in such environments (turbid-water reefs) and referred to as "alternative states" to the typical clear-water notion of reefs (Perry and Larcombe, 2003; Zweifler et al., 2021). The turbid-zone coral reef communities of the inner, central Great Barrier Reef (GBR) (Woolfe and Larcombe, 1998, 1999; Larcombe and Woolfe, 1999; Perry and Larcombe, 2003; Browne et al., 2012; Zweifler et al., 2021) are very well-known example of reefs in Case- 2 waters, with vertically compressed coral depth distributions (Morgan et al., 2016) as noted in other turbid reef systems such as in Singapore (Morgan et al., 2020).

The GBR turbid-zone coral reef communities have been the focus of considerable attention as land runoff and poor water quality is considered a major threat to the Great Barrier Reef Marine Park particularly the inshore areas (GBRMPA, 2020). Runoff from highly modified catchments can enhance the delivery of sediments, nutrients and other organic particles and could have detrimental effects by reducing the available light for seagrass and corals in the inner GBR (GBRMPA, 2020) and elsewhere in the world (Morgan et al., 2020). Conversely, reduced light availability could have "beneficial" effects and reduced levels of coral bleaching in turbid, coastal coral reef environments during heat waves has now been noted in many studies (Guest et al., 2012, 2016; Van Woesik et al., 2012; Cacciapaglia and Van Woesik, 2016; Fisher et al., 2019; Mies et al., 2020; Sully and Van Woesik, 2020), including the inshore GBR (Morgan et al., 2017). This increased resilience could be related to turbidity reducing light levels and reducing or ameliorating the physiological stress associated with the combined effects of light and elevated water temperatures (Sully and Van Woesik, 2020). To further understand these possible detrimental or "beneficial" effects of turbidity requires a better understanding of light characteristics of turbid-zone reef communities. 
In two recent studies involving vertical profiling of light in very turbid waters (elevated suspended sediment concentrations caused by dredging) preferential attenuation of shorter blue wavelengths was noted in addition to overall loss of light (Jones et al., 2016; Fearns et al., 2019). This resultant shift in underwater colour spectrum to the green/yellow waveband, which is less photosynthetically useful (Gallegos et al., 2009; Falkowski and Raven, 2013), could have implications for benthic photoautrophs (Jones et al., 2016). In this study, we further examine the effects of NAPs on quantity and quality of underwater light using elevated SSCs caused by dredging to derive wavelength specific light attenuation coefficients by water column profiling using a hyper-spectral radiometer. An empirical spectral solar irradiance model was developed to describe the underwater light spectrum and how it changes with sun-angle, water depth and suspended sediment concentration. Measurements were also made of spectral changes during a wind/wave natural resuspension event using an in situ multi-spectral radiometer. The model was used to define the exposure conditions for a laboratory-based exposure study to investigate sublethal physiological effects of a light sensitive coral incubated under different light quality and quantity scenarios.

\section{MATERIALS AND METHODS}

\section{Site Description}

Fieldwork was conducted in the inner central Great Barrier Reef (GBR) in Cleveland Bay and on the reefs around Magnetic Island (Figure 1). The oceanographic and sedimentary setting of the bay has been described by Larcombe et al. (1995) and the turbid-zone reef communities have been the subject of several studies associated with understanding sedimentary processes, transport and fate, and the effects of watershed development on reef growth in "marginal" (cf Perry and Larcombe, 2003) environments (Carter et al., 1993; Larcombe et al., 1995, 2001; Lou and Ridd, 1996; Larcombe and Woolfe, 1999; Orpin et al., 1999, 2004; Anthony et al., 2004; Browne et al., 2010, 2012, 2013; Lambrechts et al., 2010; Bainbridge et al., 2012; Orpin and Ridd,

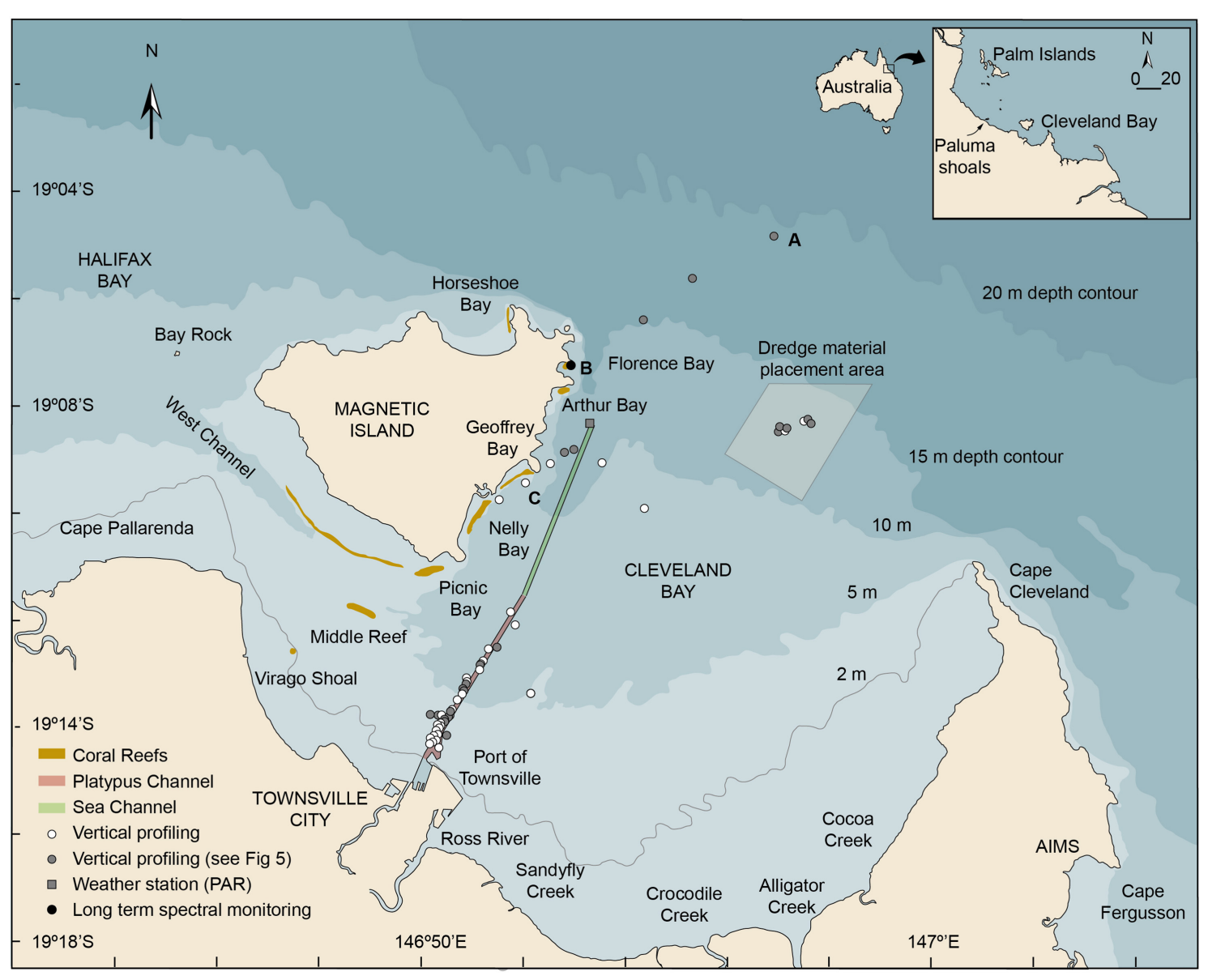

FIGURE 1 | Location map showing Cleveland Bay and Magnetic Island off the coastal city of Townsville in the inner central Great Barrier Reef (Australia) showing the locations of (a) the multispectral light logger deployment in Florence Bay $\left(19.121917^{\circ}, 146.883167^{\circ}\right)$, (b) the vertical light and turbidity profiling sites conducted beside the shipping channel, the reefs off Magnetic Island, in the dredge material placement area (DMPA), and seaward of the $15 \mathrm{~m}$ isobath, (c) the Cleveland Bay weather station $\left(-19.140556^{\circ} 146.889537^{\circ}\right)$ where above water PAR levels were recorded (AIMS, 2020). The inset figure shows the location of Cleveland Bay in the inner central Great Barrier Reef (GBR) region and coral collection sites near the Palm Islands. 
2012; Perry et al., 2012; Macdonald et al., 2013; Delandmeter et al., 2015; Whinney et al., 2017).

Briefly, Cleveland Bay is a shallow (15 $\mathrm{m}$ at its seaward edge) northward-facing embayment of around $325 \mathrm{~km}^{2}$ located off the coastal city of Townsville in Northern Queensland, Australia (Figure 1). The bay is landlocked around its southern and eastern sides by the mainland and bordered by Magnetic Island, a granitic continental high island on its north-western margin (Figure 1). On the SE of the island there are a series of bays with welldeveloped fringing reefs-Florence Bay, Arthur Bay, Geoffrey Bay, Nelly Bay and Picnic Bay-and on the southern section a large detached reef, Cockle Bay (Hopley, 1982) (Figure 1). The reefs are composed of hard and soft corals and algae (Bull, 1982; Mapstone et al., 1992; Kaly et al., 1994) overlying accumulations of non-biogenic sediments (Hopley, 1982).

The bay is naturally very turbid and resuspension of bottom sediment by wave action augmented to some extent by tides and currents is the most significant long-term contributor to elevated SSCs (Larcombe et al., 1995, 2001; Lou and Ridd, 1996; Orpin et al., 1999, 2004; Anthony et al., 2004; Orpin and Ridd, 2012; Macdonald et al., 2013; Luter et al., 2021). Background SSCs in Cleveland Bay are typically $<5 \mathrm{mg} / \mathrm{L}^{-1}$ (Larcombe et al., 1995), and $1-2 \mathrm{mg} / \mathrm{L}^{-1}$ on the reefs around Magnetic
Island (Waterhouse et al., 2021), but winds sufficient to cause resuspension of bottom sediments in the bay at $5 \mathrm{~m}$ depth occur on an estimated 220 days per year, and higher energy events sufficient to cause resuspension of bottom sediments at $15 \mathrm{~m}$ depth on 40 days per year (Figure 2A) (Orpin et al., 1999; Orpin and Ridd, 2012).

The frequent resuspension requires annual or sometimes biannual maintenance dredging of two connected shipping channels to allow safe passage of cargo ships (Figure 1). Currently, the majority of the dredging is performed by an $85 \mathrm{~m}$ long ocean-going trailing arm suction dredge (TSHD) that has two trailing arm suction heads which are lowered and dragged along the seafloor, dredging the seabed either side of the vessel (Figures 2B,C). Turbidity generation is associated with disturbance of the seabed by the drag heads and by propeller wash and by dredge material placement at the $3.7 \times 3.7 \mathrm{~km}$ dredge material placement area (DMPA) located in the bay itself (Figures 1, 2B).

\section{Turbidity and Light (Spectrum) Time Series}

From 28 May 2017 to 27 June 2017 underwater measurements of photosynthetically active radiation (PAR, 400-700 nm), turbidity and depth $(\mathrm{m})$ were measured at $15 \mathrm{~min}$ intervals (averaging for

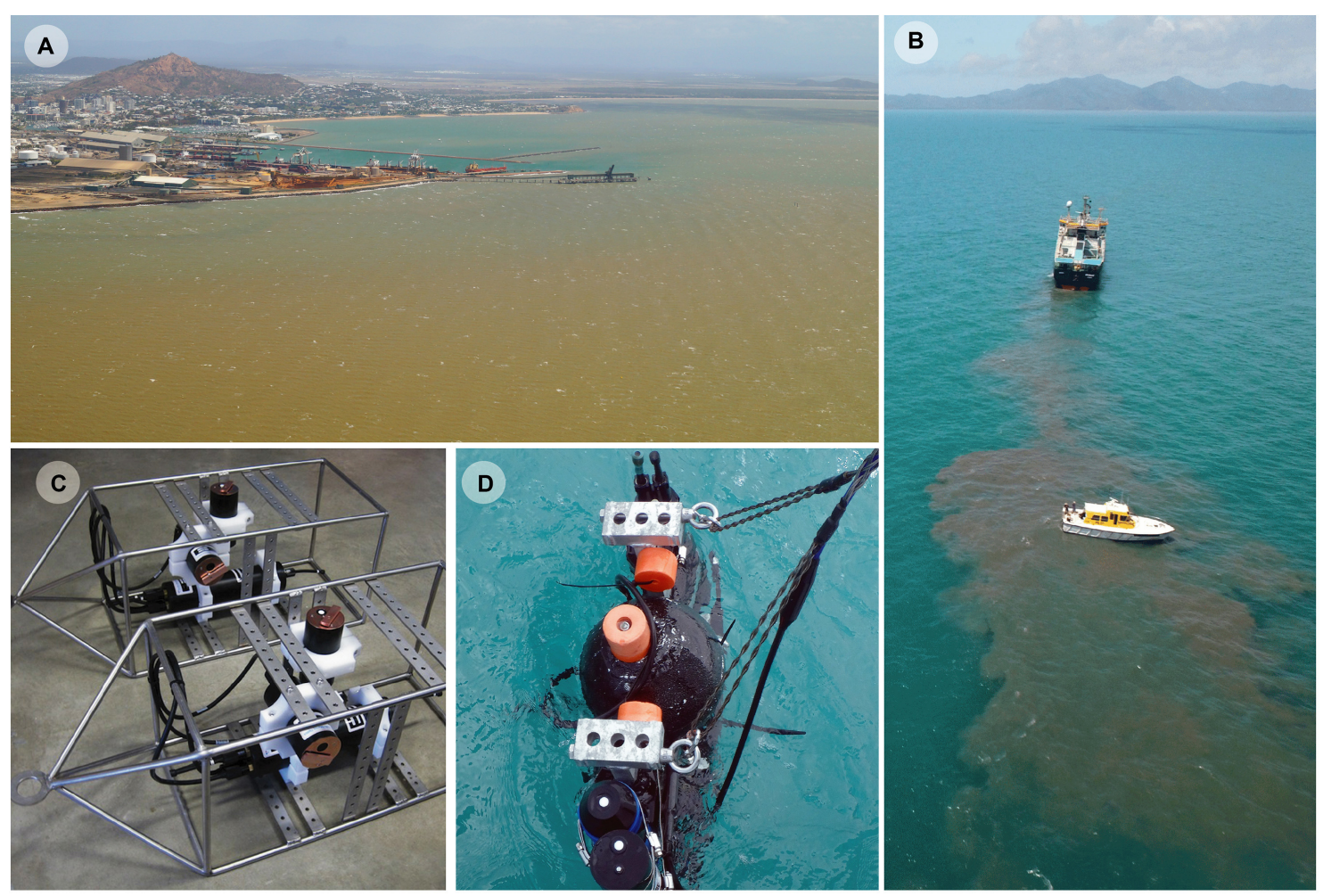

FIGURE 2 | (A) Aerial photograph of Cleveland Bay on 9 Sept 2013 during a period of elevated wind speeds. The turbidity is a natural event and not caused by dredging. (B) Research vessel with scientists vertically profiling a sediment plume from an $85 \mathrm{~m}$ long ocean-going trailing arm suction dredge (TSHD) disposing sediment at the dredge material placement area in Cleveland Bay, (C) Two upward facing IMO-MS8 eight wavelength multispectral irradiance sensors and sideways facing IMO-NTU turbidity sensors in stainless steel frames used on the reefs at Florence Bay to measure changes in light quality, quantity and water cloudiness during natural suspension events, (D) a combined USSIMO hyper-spectral radiometer and IMO-NTU turbidity sensor which was placed in plumes generated by dredging (or dredge material disposal) and allowed to slowly sink, recording turbidity and underwater irradiance at wavelengths between 400 and 700 nm. 
$10 \mathrm{~s}$ ) using sensors attached to a seabed mounted stainless steel instrument platform in Florence Bay (Figures 1, 2C). Permitting restrictions prevented deployment of the sensors on the reef itself, so the platform was placed at the very base of the reef slope at $8.5 \mathrm{~m}$ on a sandy seabed. Instruments included a vertically mounted IMO-MS8 eight wavelength (425, 455, 485, 515, 555, 615,660 , and $695 \mathrm{~nm}$ ) multi-spectral irradiance sensor and a horizontally-mounted IMO-NTU turbidity sensor, and were both connected to an IMO-DL3 data logger with built-in depth and temperature sensors [In situ Marine Optics (IMO), Perth, Western Australia] (Figure 2D). To prevent biofouling, the MS8 and turbidity sensors have copper-based wiper mechanisms that sweep over the sensors every $15 \mathrm{~min}$ and park over the sensors when not sampling.

PAR data was calculated from the 8 wavelengths by interpolating to higher resolution $1 \mathrm{~nm}$ spacing using the approx function from the stats package in R (R Core Team, 2020), and then summing across all estimated values from 400-700 nm to calculate the total interpolated Photosynthetically Available Radiation (hereafter simply PAR) expressed as an instantaneous value ( $\mu$ mol photons $\mathrm{m}^{-2} \mathrm{~s}^{-1}$ ) or on a daily basis as a daily light integral (DLI, mol photons $\mathrm{m}^{-2} \mathrm{~d}^{-1}$ ) calculated by summing the per second quantum flux measurements over the day (Fisher et al., 2015; Jones et al., 2015). Simple linear interpolation between the peak wavelength of each of the 8 sensors is a relatively robust means of estimating PAR as there is considerable overlap in the spectral sensitivity of each of the individual sensors for the MS8 multi-spectral loggers. Photosynthetically usable radiation (PUR), which is a product of the light availability (PAR) and absorption efficiency (Morel, 1978) was also calculated using equation 1 .

$$
P U R=\int_{400}^{700} \operatorname{PAR}(\lambda) A
$$

based on absorption coefficients (for symbiotic algae of corals) digitised from Figure $2 \mathrm{~b}$ of Hennige et al. (2009), and as shown in Figure 5A.

To compliment the in situ measurements, surface measurements of PAR were obtained from an instrument mounted on a channel marker buoy (nominally $10 \mathrm{~m}$ above sea level) situated $1.9 \mathrm{~km}$ south of Florence Bay (Figure 1, $19.140906^{\circ}, 146.889565^{\circ}$; AIMS, 2020).

\section{Vertical Water Quality Profiling}

Over a 4-d period (12-15 September 2016), 94 light and turbidity vertical profiles were measured in and just outside of Cleveland Bay using a USSIMO hyper-spectral radiometer (In Situ Marine Optics, Perth, Australia) and IMO-NTU turbidity sensor (Figure 2D). The USSIMO incorporates a Carl Zeiss UV/VIS miniature monolithic spectrometer module as the internal light recording device providing irradiance measurement values at nanometre spectral spacing with instrument tilt and temperature sensors (Antoine et al., 2017). The instruments were mounted vertically on an aluminium frame, with the radiometer orientated upwards and turbidity sensor downwards. The frame was designed to sit vertically in the water column using polystyrene floats and was made slightly negatively buoyant using lead weights. Sampling involved holding the instrument frame at $0.5 \mathrm{~m}$ depth in plumes created by the dredging activities (Figure 2B) and then allowing the instrument frame to drift away from the boat and slowly sink (free-fall) at a rate of $0.5 \mathrm{~m} / \mathrm{s}$ through the plume recording light and turbidity and depth until it reached the seabed. Sampling rates were up to $5 \mathrm{HZ}$ with 20-250 samples taken per cast depending on depth. A reference USSIMO radiometer was also positioned on the mast of the survey vessel and was used to identify reductions in light during the profile as a result of intermittent clouds (see below). Profiles were conducted in the shipping channel and turning basin and in shallower water either side of the channel ( $n=76$ sites, depths of up to $12 \mathrm{~m}$ ) in the spoil ground area ( $n=12$ sites, depths up to $\sim 11-13 \mathrm{~m}$ ) beside Geoffrey Bay reef ( $n=3$ sites depths) and outside of Cleveland Bay ( $n=3$ sites, depths of 16-21 m) (Figure 1).

At the start of each profile a water sample was collected using a Niskin ${ }^{\mathrm{TM}}$ bottle (General Oceanics, Miami, Florida, US) and triplicate water samples were drawn from the Niskin bottle and subsequently filtered onto Whatman (Cytiva, Marlborough, MA, USA) $47 \mathrm{~mm} \mathrm{GF/F} \mathrm{filters} \mathrm{(nominal} \mathrm{pore} \mathrm{size} 0.7 \mu \mathrm{m}$ ), using $100 \mathrm{~mL}$ of distilled water to rinse the container, filter funnel and filter pads of salts. Filters were then dried overnight in a $65^{\circ} \mathrm{C}$ oven and weighed with a precision balance (capable of weighing to $0.0001 \mathrm{~g}$ ) and used to generate the relationship between SSC and turbidity (NTU).

\section{Light Exposure Experiments}

Studies examining the effect of light quantity and quality on the branching coral Pocillopora verrucosa (Ellis and Solander, 1786) were conducted at the National Sea Simulator (SeaSim) aquarium facilities at the Australian Institute of Marine Science (AIMS, Townsville), using corals collected from 3-5 $\mathrm{m}$ depth from the Palm Islands, central GBR (Figure 1). Fragments from four colonies were collected using a mallet and chisel and transported to the SeaSim where they were further fragmented $(\sim 5-9 \mathrm{~cm}$ length) and glued onto numbered aragonite plugs. Fragments were left to recover for 1 month in $1,200 \mathrm{~L}$ holding tanks with flow-through seawater maintained at $27^{\circ} \mathrm{C}, 36$ PSU salinity, and under a 12-h light: dark (L:D) cycle of ascending and decreasing light levels, equivalent to a DLI of $6 \mathrm{~mol}$ photons $\mathrm{m}^{-2} \mathrm{~d}^{-1}$. Throughout the holding and experimental periods, an enriched Artemia spp. (targeted concentration in tanks of 0.5 nauplii $\left.\mathrm{mL}^{-1}\right)$ and a mix of microscopic algae $\left(2,000\right.$ cells $\left.\mathrm{mL}^{-1}\right)$ were fed daily.

Utilising the same tank system, control mechanisms and custom-made LED light fittings as recently described in Luter et al. (2021), corals were exposed to four different experimental light scenarios for 28-d. Experiments were conducted at $27^{\circ} \mathrm{C}$ and the individual $1200 \mathrm{~L}$ tanks received fresh seawater at a rate of 2,500 $\mathrm{mL} \mathrm{min}^{-1}$ resulting in 3 complete turnovers per day. Each scenario consisted of either a high or low light level in combination with a "normal" or "green-yellow shifted" spectrum (see Results section, Figure 9). There were two replicate tanks for each scenario, with a total of eight fragments per treatment $(n=4$ per tank, representing each genotype). Unlike Luter et al. 
(2021), no suspended sediments were added to the tanks during the exposure period.

All corals were photographed and weighed, using the buoyant weight method (Spencer Davies, 1989), at the start and end of the experiment. Following the 28-d exposure, coral tissue was removed by air blasting in $30 \mathrm{~mL}$ of $0.5 \mu \mathrm{m}$ filtered seawater. The resulting tissue slurry was homogenised for $60 \mathrm{~s}$, the exact volume recorded, and aliquots taken for symbiotic dinoflagellate density ( $1 \mathrm{~mL}$, fixed in $10 \%$ buffered formalin), pigments $(1 \mathrm{~mL})$ and lipid $(10 \mathrm{~mL})$ analyses. The surface area of corals was determined using the wax-dip method (Stimson and Kinzie, 1991). To determine symbiotic dinoflagellate density, a volume of $0.4 \mathrm{~mm}^{3}$ from each aliquot was counted six times using a Neubauer hemocytometer (LO - Laboroptik Ltd, Lancing UK) containing $8 \mu \mathrm{L}$ of homogenised solution.

To determine pigment concentrations, algal pellets from coral blastate samples were weighed and ground with a small amount of $100 \%$ acetone using a glass mortar and pestle, settled in ice. The ground blastate was transferred to a $10 \mathrm{~mL}$ centrifuge tube, vortexed for $30 \mathrm{~s}$ and sonicated in an ice-water bath for $20 \mathrm{~m}$ in the dark, followed by an overnight incubation $(\sim 15 \mathrm{~h})$ at $4^{\circ} \mathrm{C}$ in the dark. Extracts were then centrifuged at 2,500 rpm for $5 \mathrm{~min}$ at $-2^{\circ} \mathrm{C}$ and transferred to $10 \mathrm{~mL}$ volumetric flasks using Pasteur pipettes. Three $\mathrm{mL}$ of $100 \%$ acetone was added to each sample before repeating the vortex and sonication steps. The second extract was left for $2 \mathrm{~h}$ before centrifugation, and then both extracts were combined. One $\mathrm{mL}$ of water was added to each flask and then made up to $10 \mathrm{~mL}$ with $100 \%$ acetone to render a final extract of $90 \%$ acetone:water. Sample extracts required dilution with $90 \%$ acetone:water to have a concentration within the linear range of the standard calibration for all pigments. The final extract was filtered through a $0.2 \mu \mathrm{m}$ membrane filter (Whatman, anatope) prior to analysis by HPLC (high performance liquid chromatography) using a Waters Alliance HPLC system (Waters, USA), comprising a 2695XE separations module with column heater and refrigerated autosampler and a 2996 photo-diode array detector. A detailed description of the HPLC method can be found in Clementson (2013). Pigments were identified by retention time and absorption spectrum from a photo-diode array (PDA) detector and concentrations of pigments were determined from commercial and international standards (Sigma; DHI, Denmark). Total lipids and lipid classes were identified by extracting freeze-dried blastate samples following the procedures outlined in Luter et al. (2021), with lipid classes determined using the Iatroscan MK $6 \mathrm{~s}$ thin layer chromatography flame ionisation detector (Mitsubishi Chemical Medience, Tokyo, Japan). Detailed methods of lipid extraction and quantification procedures can be found in Conlan et al. (2017).

Generalised linear mixed models (GLMM) were used to examine the strengths of treatment effects and assess the differences between individual light scenario treatments. Individual GLMMs were fit for each of the response variables assessed. Since corals can both grow and shrink, a Gaussian distribution was used for growth (buoyant weight expressed as $\%$ of initial weight) as this variable can theoretically take positive and negative values and was normally distributed, whereas a
Gamma distribution was used for zooxanthella density (symbiont density), pigment concentration ( $\mu \mathrm{g} \mathrm{Chl} \mathrm{a} \mathrm{cm}^{-2}$ ), total lipids and the ratio of storage to structural lipids, as these variables were continuous on the scale of $>0$. The glmer function in the $\mathrm{R}$ package lme4 (Bates et al., 2015) was used to fit the models using tank as a random effect. Relative model weights (Burnham and Anderson, 2002) were calculated using AICc values for the model including the treatment effect and a null model including only the random tank effect. To compare individual treatment effects a Bayesian approach based on posterior contrasts was used. Integrated nested Laplace approximation (INLA) for approximating posterior distributions (see Rue et al., 2009) was used to fit Bayesian models of the equivalent GLMM design. A posterior probability similarity of $0.95 \%$ or greater was used to identify statistically similar groupings.

\section{RESULTS}

\section{Turbidity and Light (Spectrum) Time Series}

Over the 31-d deployment, which included the austral winter solstice on 21 June, the maximum instantaneous above water (surface) light levels varied more than 2-fold, from $750 \mu \mathrm{mol}$ quanta $\mathrm{m}^{2} \mathrm{~s}^{-1}$ during an overcast day on June 11 to $\sim 1,600 \mu \mathrm{mol}$ quanta $\mathrm{m}^{2} \mathrm{~s}^{-1}$ during a series of cloud-free days (Figure $3 \mathrm{~A}$ ). The maximum daily instantaneous underwater PAR varied over an order of magnitude from $<10 \mu$ mol quanta $\mathrm{m}^{2} \mathrm{~s}^{-1}$ on 19 June to $>150 \mu \mathrm{mol}$ quanta $\mathrm{m}^{2} \mathrm{~s}^{-1}$ on 11 days of the deployment $17-21$ June (Figure 3A).

In the first week of June a 7-d natural turbidity event occurred caused by a period of increased wind speeds (data not shown), and average daily nephelometry-derived SSCs (based on a NTU to SSC conversion in Figure $6 \mathrm{C}$ ) reached $\sim 10 \mathrm{mg} \mathrm{L}^{-1}$ (including an SSC of $55 \mathrm{mg} \mathrm{L}^{-1}$ at 05:30 h on 1 June) (Figure 3B) compared to normal background SSCs of 1-2 mg (Waterhouse et al., 2021).

To examine the effects of elevated water turbidity and clouds on the underwater spectral distributions, wavelength specific underwater irradiance values were averaged over a $2 \mathrm{~h}$ period centred on solar culmination each day and standardised to a mean of zero and standard deviation of 1 . The standardised profiles showed considerable variability but mostly in the shorter blue and blue/green wavelengths $(415,455,485$, and $515 \mathrm{~nm})$ (Figure 3C).

Inspection of Figures 3A,B shows the deployment occurred for several days where there was either (1) high or (2) low turbidity in combination with either (3) high or (4) low surface light (caused by the absence or presence of clouds). Figure 3D shows the normalised spectral response of 2 days in each of these 4 combinations, revealing preferential loss of the blue light wavelengths invariably occurred during periods of high turbidity, or expressed another way, notable spectral changes did not occur when absolute underwater light levels were reduced by clouds alone.

Since the spectral changes were associated with a reduction in blue light an index was calculated based on the ratio of blue light $(455 \mathrm{~nm})$ to green light $(555 \mathrm{~nm})$. This blue/green ration value fell sharply to $<0.4$ during the week-long turbidity event 

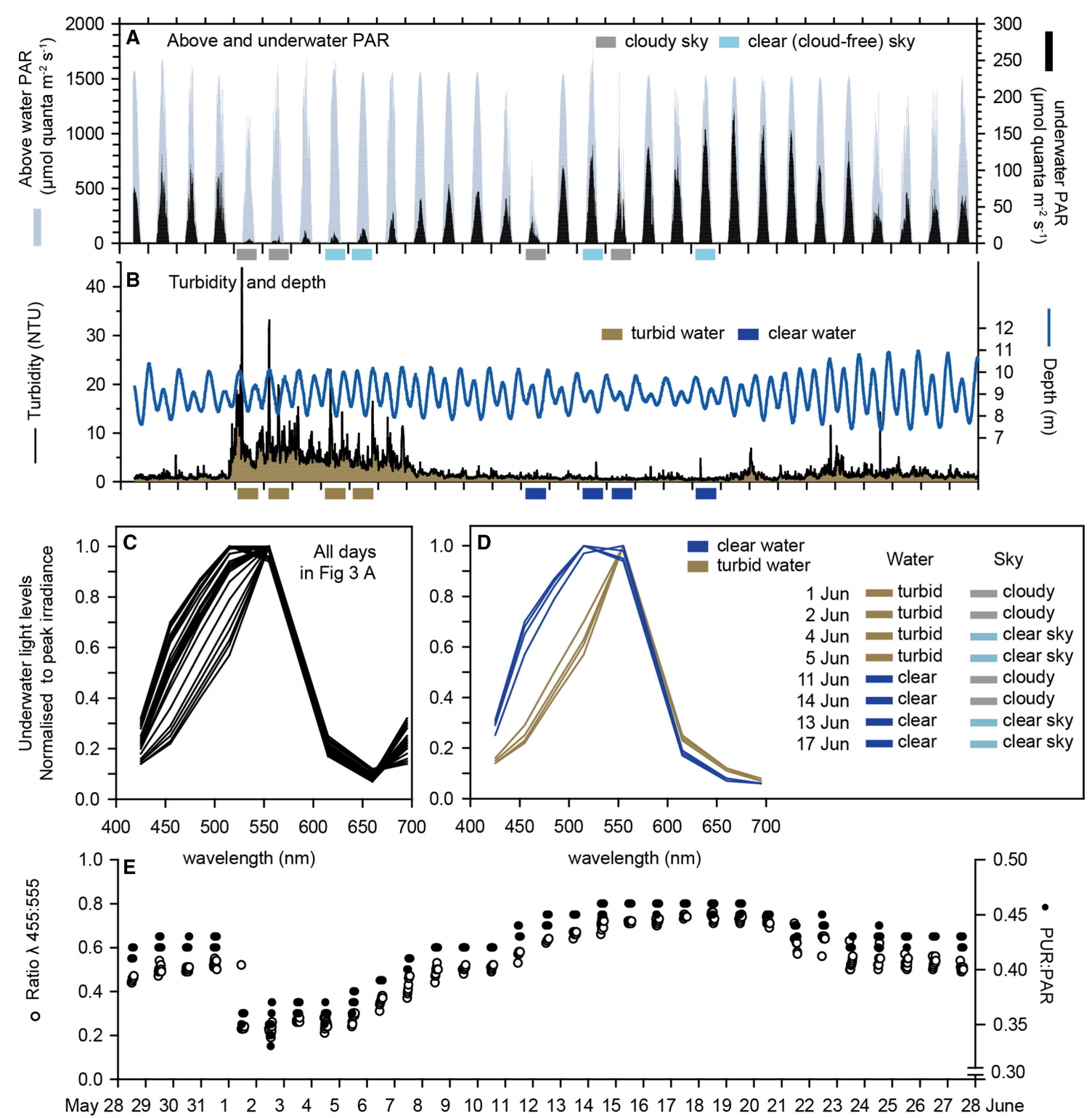

FIGURE 3 | Multispectral sensor data: (A) Underwater PAR at $8 \mathrm{~m}$ depth at Florence Bay and above water PAR at the weather station beside Florence Bay (Figure 1) from 28 May to 28 June (2017) which encompassed the austral winter solstice (21 June). (B) Turbidity (NTU) at the seabed (8 m) at Florence Bay and depth (m). (C) The ratio of $\lambda 455 \mathrm{~nm}$ to $\lambda 555 \mathrm{~nm}$ light and PUR/PAR. (D,E) Normalised irradiance spectra from the underwater multispectral light sensor at Florence Bay over a $2 \mathrm{~h}$ period centred on midday for all days and 8 days showing the effects of high and low turbidity with and without cloud cover (see text).

returning to values $>0.6$ when SSC levels fell back to $1 \mathrm{mg} \mathrm{L}{ }^{-1}$ (Figure 3E). The PUR:PAR ratio showed similar changes and a $25 \%$ reduction during the turbidity peak (Figure $3 \mathrm{E}$ ) on account of the spectral changes.

\section{Vertical Water Quality Profiling}

Representative vertical spectral light profiles using the hyperspectral radiometer are shown in Figure 4 for a deeper water site (20 m depth) outside Cleveland Bay (Site A in Figure 1), and a shallower site ( $8 \mathrm{~m}$ depth) beside the coral reef at Geoffrey Bay (Site B in Figure 1). Both sites had very low SSCs $\left(\sim 1 \mathrm{mg} \mathrm{L}^{-1}\right)$ at the time of sampling.
In the offshore site, the upper $0.5 \mathrm{~m}$ had a relatively even distribution of blue, green and red wavelengths and there was rapid loss of red light with increasing depth to very low values by $8-10 \mathrm{~m}$ (Figures $4 \mathbf{A}, \mathbf{B}$ ). Blue light $(450-500 \mathrm{~nm}$ ) was also attenuated but at a lower rate as indicated by the vertically averaged water column attenuation coefficient (Figure 4C). At the seabed at $20 \mathrm{~m}$ the peak wavelength was $475 \mathrm{~nm}$ in the blue part of the spectrum (Figures 4A,B).

Beside the reef there was also an even distribution of blue, green and red wavelengths in the upper $0.5 \mathrm{~m}$ and also a loss of red light with depth (Figures 4E,F). However, as indicated by the increase in the vertically averaged water column attenuation 


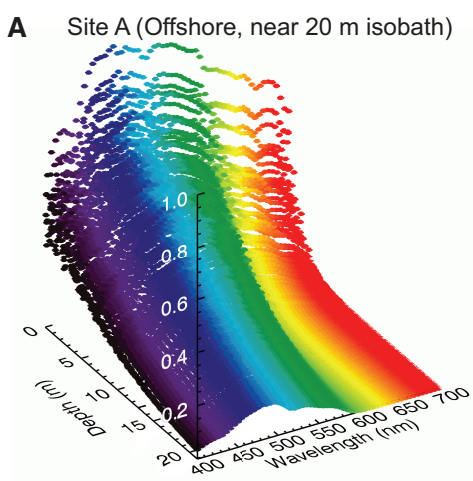

D Site C (inshore, beside a coral reef)

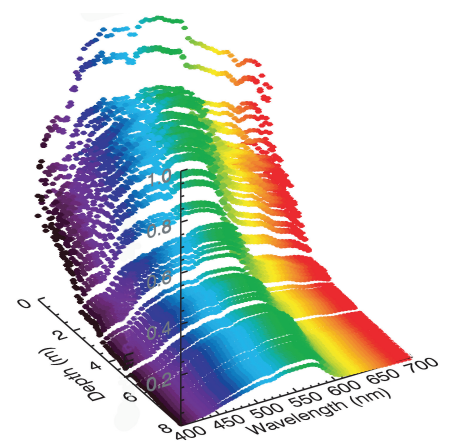

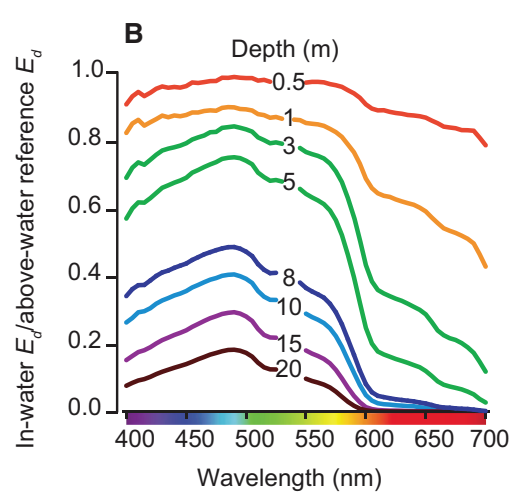

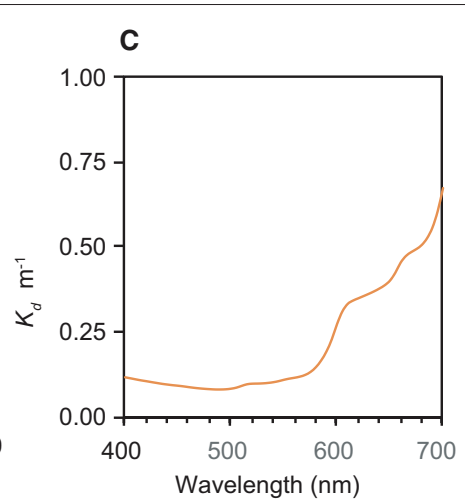

E

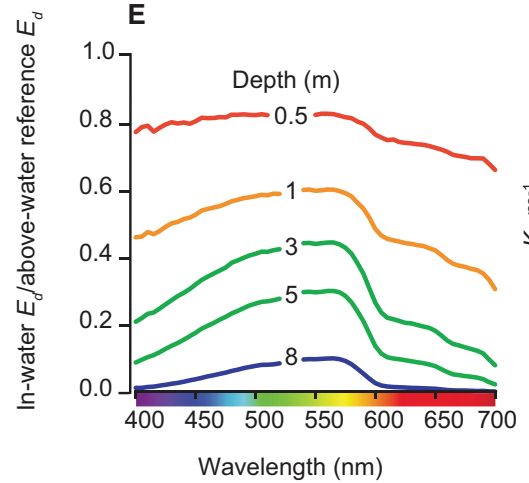

$\mathbf{F}$

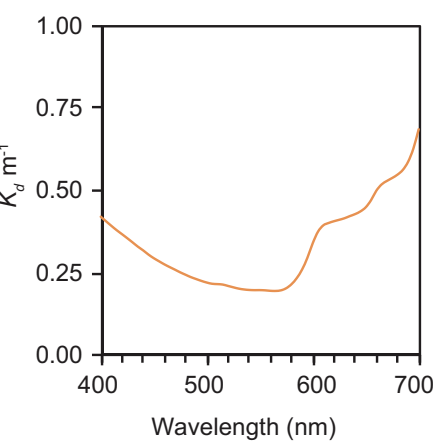

FIGURE 4 | Vertical light profiling study with the hyper-spectral radiometer for site (A) (furthest offshore) and site (C) (off Geoffrey Bay) (see Figure 1) in September 2016, showing: (A,D) 3D spectral profiles of $\mathrm{W} / \mathrm{m}^{2} / \mathrm{nm}$ according to depth and wavelength $\mathbf{( B , E ) ~ n o r m a l i s e d ~ d o w n w e l l i n g ~ i r r a d i a n c e ~ s p e c t r a ~ a n d ~}(\mathbf{C}, \mathbf{F})$ vertically averaged spectral attenuation coefficients $K_{d}$. $(n m)$.

coefficient (Figure 4F) there was also much greater attenuation of blue wavelengths with depth. Near the seabed ( $8 \mathrm{~m}$ depth), the peak wavelength was $575 \mathrm{~nm}$ in the green-yellow part of the spectrum (Figures 4A,B).

Figure 5A shows the normalised (in-water Ed divided by above-water reference Ed) spectral profiles and Figure $5 \mathbf{B}$ the vertically average attenuation coefficient at single depth of $3 \mathrm{~m}$ for 23 vertical profiles where light was detectable at all wavelengths, including profiles collected outside the bay beyond the $15 \mathrm{~m}$ depth contour, in the dredge material placement area (DMPA), in or within $50 \mathrm{~m}$ of the Platypus channel, and sites off the reef slope of Geoffrey Bay. A colour-coding scheme based on the mean turbidity (at $3 \pm 0.1 \mathrm{~m}$ depth) per profile is used to indicate turbidity which ranged from 1 to 11.1 NTU. At increasingly higher turbidity there was loss of light, and also proportionally higher $\mathrm{Kd}$ in the shorter blue wavelengths, resulting in an increase in the peak wavelengths from $<500 \mathrm{~nm}$ to $575 \mathrm{~nm}$. Also shown in Figure $\mathbf{5 A}$ is the absorption spectra of the symbiotic dinoflagellates of corals (digitised from Figure $2 \mathrm{~b}$ in Hennige et al., 2009), indicating light is comparatively poorly absorbed in this part of the spectrum.

Figure 5C shows a principal coordinate analysis (PCO) of the 23 sites based on the hyper-spectral data. Analyses were performed in PRIMER 6 (Plymouth, UK) using Euclidean distances and Spearman Rank correlations to identify wavelengths that contribute most to the differences observed (Figure 5C). The shapes correspond to sampling locations and colour of the shape corresponds to the turbidity, which decreased from the highest values (red; left of the ordination) to the lowest values (green; right of the ordination). The wavelengths contributing most to the shift of samples to the right of the ordination include 490,510, and $525 \mathrm{~nm}$ (blue/green), whereas the wavelengths contributing least include 690, 695, and 700 (red wavelengths) (Figure 5C).

\section{Empirical Spectral Solar Irradiance Model}

From the vertical profiles a simple, multiple component empirical optical model was developed to estimate the spectral reduction of underwater light as a function of solar angle, suspended solid concentration and water depth. The first part of the model represented the input solar irradiance based on a number of clear sky, full-day time-resolved above water irradiance measurements from a dynamic above-water radiance and irradiance collector (DALEC) hyperspectral radiometer (Slivkoff, 2014).

For each wavelength $(\lambda)$, a 3 rd order polynomial was fitted to the cosine solar zenith angle $\left(\theta_{\mathrm{z}}\right)$ normalised irradiance data, and then converted to subsurface irradiance using a spectrally-independent conversion factor $\mathrm{T}=0.965$ (Morel and Antoine, 1994; Morel and Maritorena, 2001). The model was then expressed as an equation to generate estimations of the 
subsurface irradiance $\mathrm{E}_{\mathrm{d}}(-0)$, as a function of solar zenith angle and wavelength (Equation 2).

$$
\begin{aligned}
& E_{d}\left(-0, \lambda, \theta_{z}\right)= \\
& \quad T\left[C_{0}(\lambda)+C_{1}(\lambda) \theta_{z}+C_{2}(\lambda) \theta_{z}^{2}+C_{3}(\lambda) \theta_{z}{ }^{3}\right] \cos \left(\theta_{z}\right)
\end{aligned}
$$

The next component of the model incorporated the vertical irradiance and NTU profile measurements in Cleveland Bay, alongside the gravimetric total suspended solids measurements (Figure 6A). Each vertical USSIMO Irradiance profile was normalised by the second in-air reference USSIMO radiometer. All radiometer data was then screened to remove measurements where the cosine collector was tilted $>5^{\circ}$ from zenith (directly overhead). This typically removed the first $1 \mathrm{~m}$ of the vertical profile while the slow-descent instrument frame stabilised. Data from $<0.03 \%$ incident irradiance was also removed from processing, which removed near-seabed data and extremely turbid waters where light reductions could not be quantified as a function of water depth.

The exponential Beer-Lambert equation was fitted to the quality-controlled normalised irradiance data for each wavelength and sensor depth $\mathrm{z}$ in order to determine the watercolumn averaged spectral diffuse attenuation coefficients $\left(\mathrm{K}_{\mathrm{d}}\right)$ for each profile.

$$
K d(\lambda)=-\frac{\ln \left[\frac{E_{d}(z, \lambda)}{E_{d}(+0, \lambda)}\right]}{z}
$$

Solar angle normalisation of the $\mathrm{K}_{\mathrm{d}}$ data was not conducted as profiles were typically performed during high sun angles $<20^{\circ}$. To match the water column-averaged $\mathrm{K}_{\mathrm{d}}$ data, full vertical profile NTU data collected simultaneously to the irradiance data was averaged. The spectrally resolved NTU-specific and residual $\mathrm{K}_{\mathrm{d}}$ data was determined using linear regression.

The slope (NTU specific $K_{d}$ ) coefficients and the residuals are shown in Figure 6B. The residual spectral shape is strongly influenced by the absorption coefficient of water itself, whereas the spectral shape of the NTU specific coefficients are governed by particulate absorption and scattering (see Slivkoff, 2014).

An estimate of the diffuse attenuation coefficient based on NTU is then expressed as:

$$
K_{d}(\lambda)=K_{M}(\lambda)[N T U]+K_{C}(\lambda)
$$
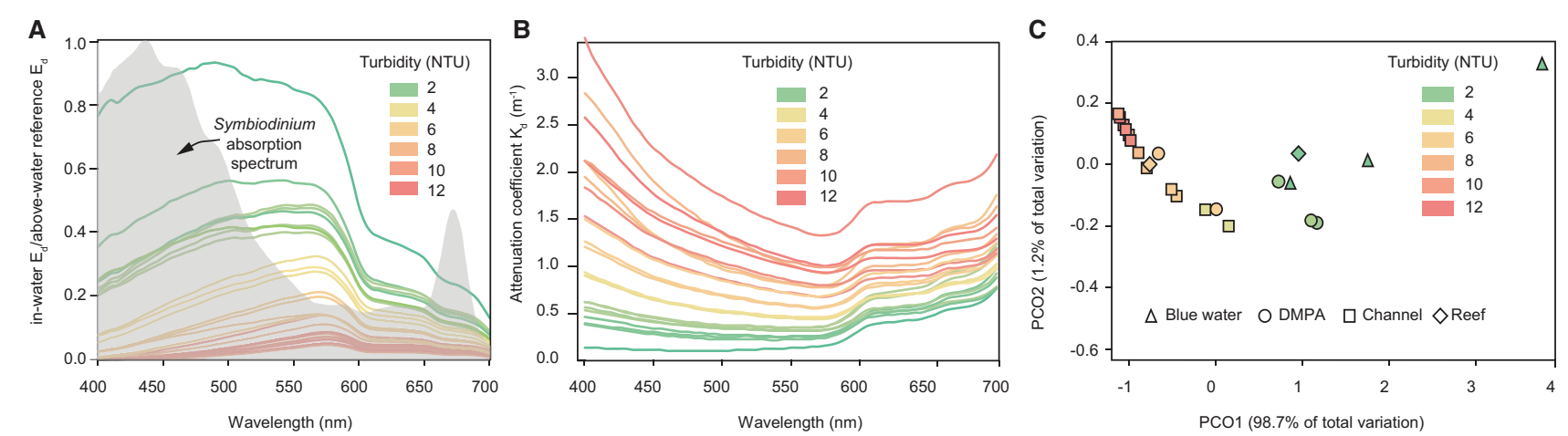

FIGURE 5 | Vertical profiling study. (A) normalised (in-water $E_{d}$ divided by above-water reference $E_{d}$ ) downwelling irradiance spectral profiles, (B) spectral attenuation coefficients at $3 \mathrm{~m}$ depth for 23 vertical light profiles with NTU values at $3 \mathrm{~m}$ depth ranging from 1 to $11.1 \mathrm{NTU}$. The grey shaded area in (A) represents the absorption spectra of isolated symbiotic dinoflagellates (of corals) digitised from Figure $2 \mathrm{~b}$ in Hennige et al. (2009). (C) Principal coordinate analysis (PCO) of spectral profiles for the same vertical profiles. Where triangles represent "blue water" profiles sampled beyond the $15 \mathrm{~m}$ depth contour outside Cleveland Bay ( $n=3$ ), "DMPA" represents samples collected in the dredge material placement area $(n=5)$, "channel" represent samples collected in the Platypus channel or $<50 \mathrm{~m}$ either side of the channel, and Reef represents samples off the reef slope near Geoffrey Bay $(n=3)$ (see Figure 1).
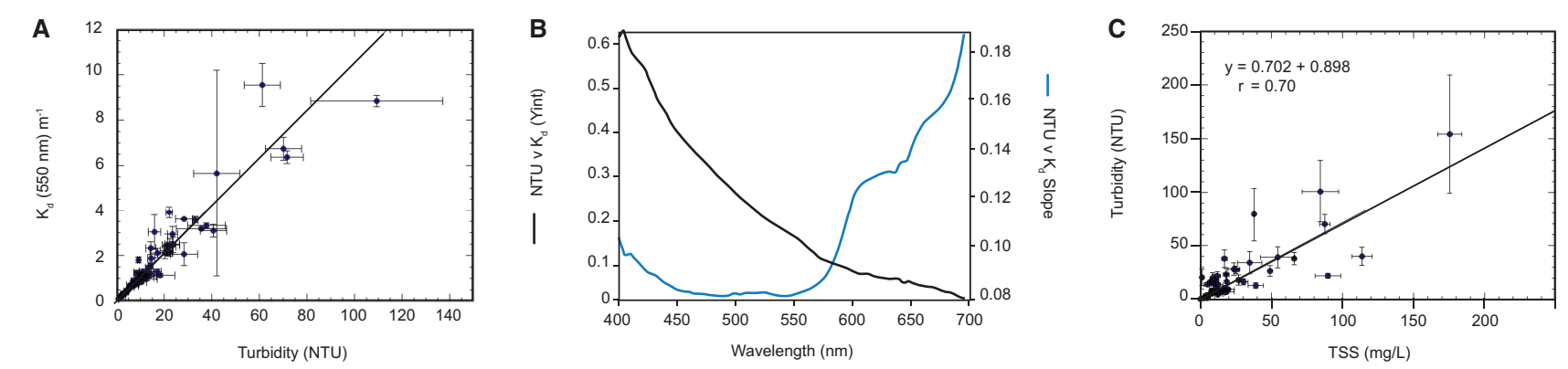

FIGURE 6 | (A) Example regression line of $\mathrm{K}_{d}(550 \mathrm{~nm})$ vs. NTU from the 94 vertical profiles (B) Regression-based spectral NTU-specific $\mathrm{K}_{d}$ coefficients (KM), Regression-based spectral residual $K_{d}$ coefficients $\left(K_{C}\right)$ (C) Surface in-situ NTU average vs. SCC from Niskin samples. 
As the goal of the modelling study is to relate light attenuation back to SSCs, a regression relating SSCs to NTU was calculated (Figure 6C). This relationship is used to express a user input TSS into NTU:

$$
N T U=A[T S S]+B
$$

Where $\mathrm{A}=0.702466$ and $\mathrm{B}=0.898$.

The final model output is determined by substituting Equation 2, 3, and 4 into the Beer-Lambert law:

$$
\begin{aligned}
& E_{d}\left(z, \lambda, \theta_{z}\right)= \\
& \quad T\left[C_{0}(\lambda)+C_{1}(\lambda) \theta_{z}+C_{2}(\lambda) \theta_{z}{ }^{2}\right. \\
& \left.\quad+C_{3}(\lambda) \theta_{z}^{3}\right] \cos \left(\theta_{z}\right) e^{-\left[K_{M}(\lambda)[A(T S S)+B]+K_{C}(\lambda)\right] z}
\end{aligned}
$$

The predictive ability of the empirical spectral solar irradiance model developed from the vertical profiling with the hyperspectral radiometer was assessed against the underwater light measurements collected using the in situ multi-spectral radiometer data on the reef at Florence Bay (Figure 3). The assessment was made using an average of measurements at $12: 00,12: 15,12: 30 \mathrm{pm}$, which bracketed the solar culmination of 12:10-12:15 pm over the deployment period. The model is based on clear sky irradiance measurements (Slivkoff, 2014) and the multi-spectral radiometer deployment included many days of clear-sky, cloudy and partially cloudy conditions (Figure 3), representative examples of which are shown in Figure 7A together with predicted surface light from the libRadtran radiative transfer model (Emde et al., 2016). Under a cloudfree (clear-sky) condition the measured surface light levels aligned exactly to the predicted irradiance but was less during a cloudy day (Figure 7A). During a partially cloudy day, surface

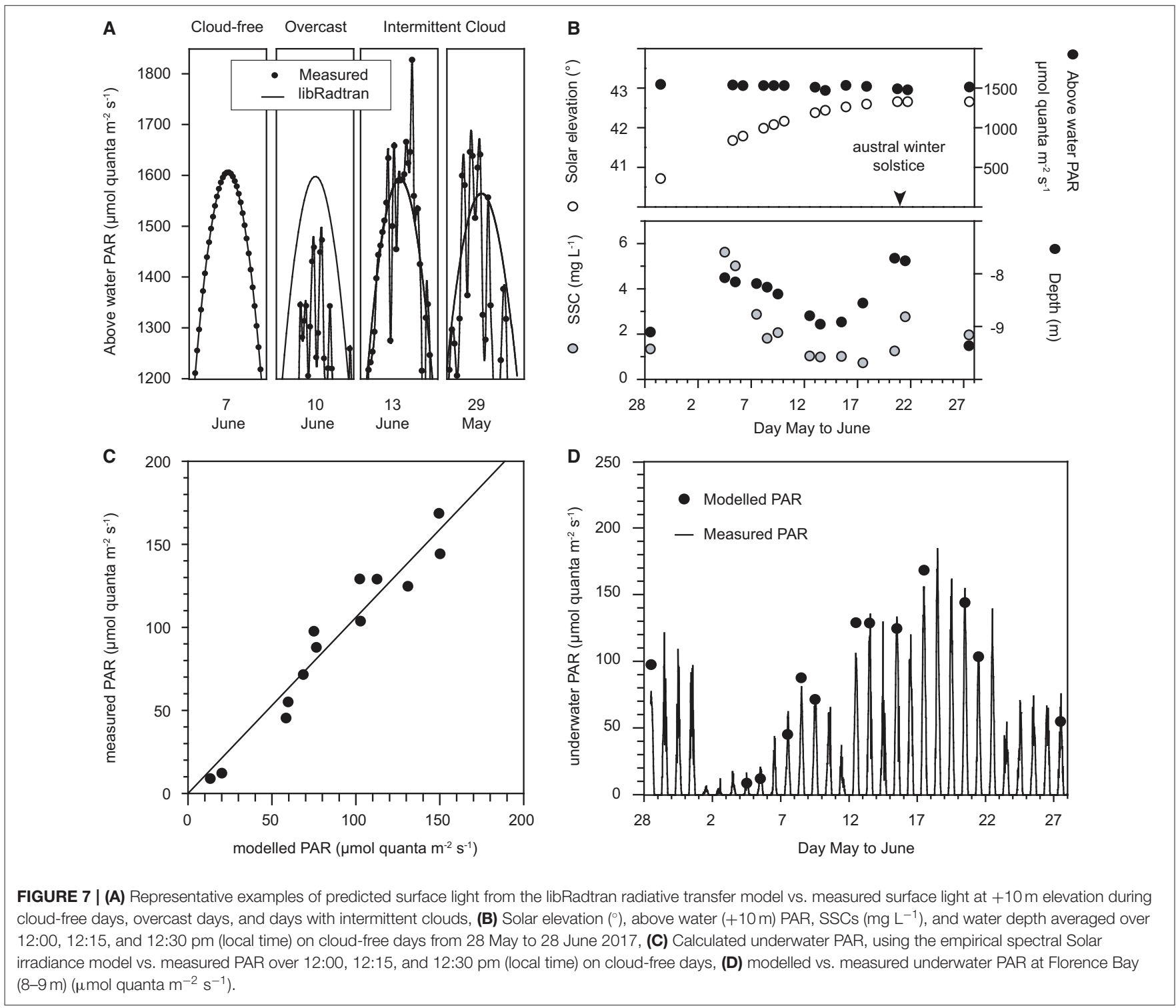


levels were both below and above the light level computed by libRadtran. The higher computed values are overirradiance associated with cloud albedo (see Discussion). Only days when the average measured noon-time irradiance was within $3 \%$ of the predicted values were used for the model assessment and a total of 14 days met this criterion. The other model inputs included the solar elevation angle (degrees from vertical, from Geoscience Australia: National Mapping Division), SSC (mg L ${ }^{-1}$, converted from turbidity readings using a multiplier of 1.25) and measured water depth $(\mathrm{m})$ which were also averaged over the noon period.

Of the 14 days the surface noon-time irradiance was $\sim 1,500 \mu \mathrm{mol}$ quanta $\mathrm{m}^{2} \mathrm{~s}^{-1}$ (Figure 7B) decreasing slightly with increasing solar elevation (from vertical) to the solstice on 21 June (Figure 7B). Water depth varied over $1.5 \mathrm{~m}$
(Figure 7B) and SSCs varied over an order of magnitude from $<1$ to $6 \mathrm{mg} \mathrm{L}^{-1}$ (Figure 7B). Underwater light levels varied over an order of magnitude from 13-150 $\mu \mathrm{mol}$ quanta $\mathrm{m}^{2} \mathrm{~s}^{-1}$ (Figure 7D). Modelled underwater PAR levels correlated very well with the measured values $\left(R^{2} 0.90\right.$, Figures 7C,D).

The empirical spectral solar irradiance model was then used to develop an optical nomograph to graphically represent the underwater PAR levels at depths of 0.5$10 \mathrm{~m}$ and at SSC concentrations ranging from 0.5 up to $40 \mathrm{mg} \mathrm{L}^{-1}$ on a $\log$ scale (Figure 8A) and linear scale (Figure 8B). The solar elevation angle for the analysis was $0^{\circ}$ from vertical (i.e., sun directly overhead) and under cloud-free conditions the PAR levels at the depth represent the maximum theoretical instantaneous light levels for
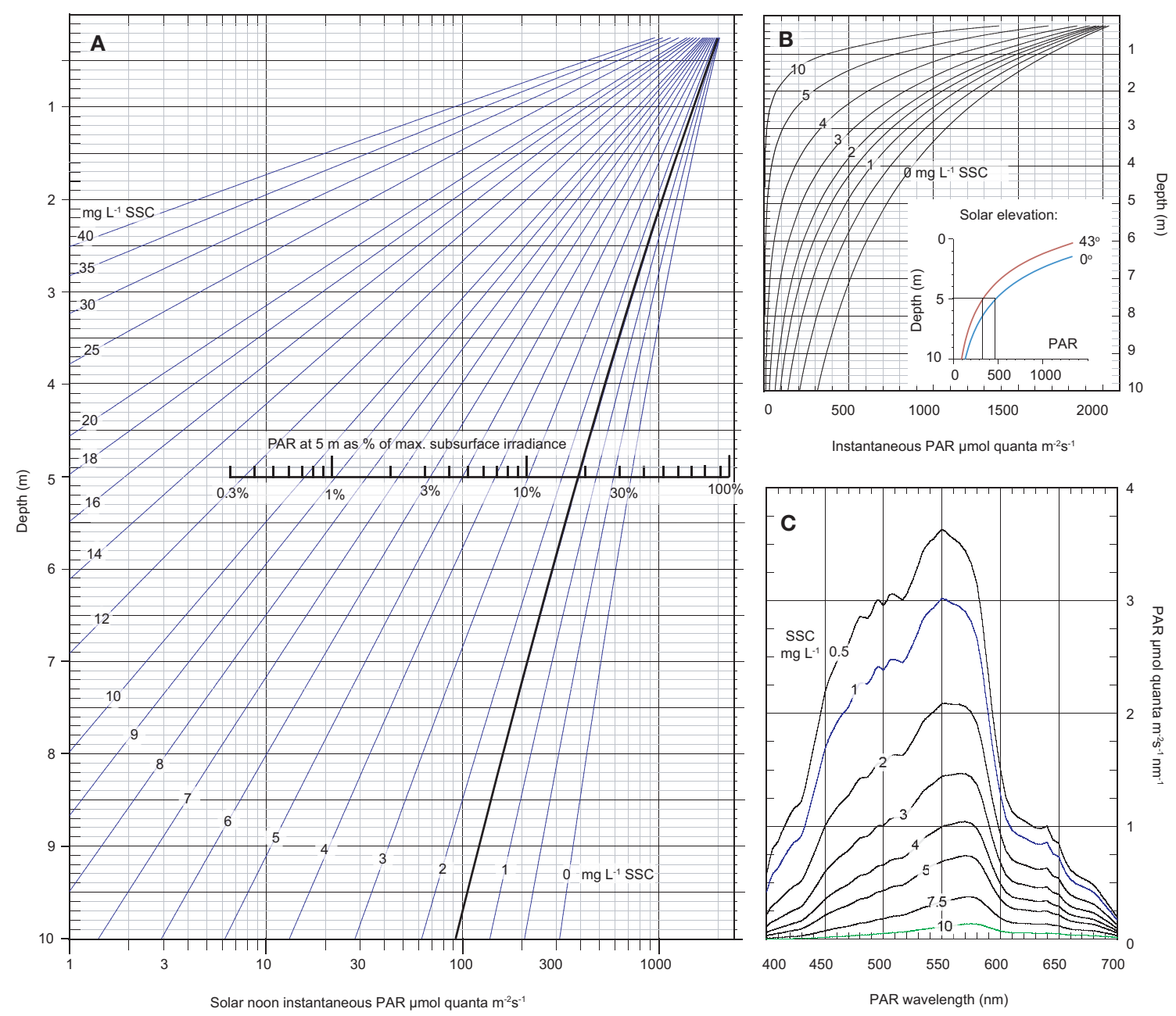

FIGURE 8 | Modelled data based on the empirical spectral solar irradiance model derived from the plume profiling exercise showing (A) an optical nomograph of maximum instantaneous PAR (400-700 nm) in $\mu$ mol quanta $\mathrm{m}^{-2} \mathrm{~s}^{-1}$ (x-axis, log scale) and as a \% of maximum subsurface irradiance, from 0.25-10 $\mathrm{m}$ water depth (y-axis) under a range of SSCs from 0-40 $\mathrm{mg} \mathrm{L}^{-1}$ and a solar elevation angle of $0^{\circ}$ from vertical (i.e., sun directly overhead), and a cloud-free day, (B) the same data as (A) but without a log scale with the inset figure showing modelled underwater light levels at $1.5 \mathrm{mg} \mathrm{L}^{-1}$ but under a solar elevation of 0 or $43^{\circ}$ from vertical (see text), (C) modelled spectral profiles in $\mu \mathrm{mol}$ quanta $\mathrm{m}^{-2} \mathrm{~s}^{-1} \mathrm{~nm}$ at $5 \mathrm{~m}$ depth under a range of SSCs from $0.5-10 \mathrm{mg} \mathrm{L}^{-1}$ at a solar elevation angle of $0^{\circ}$ from vertical and a cloud-free day. 
the nominated SSC level (empirically tied to the Florence Bay reef).

At $5 \mathrm{~m}$ depth, which is close to the maximum depth distribution of the majority of corals at Magnetic Island and local reefs (Morgan et al., 2016; Ceccarelli et al., 2020), an SSC of $1.5 \mathrm{mg}$ $\mathrm{L}^{-1}$, which is the median background SSCs at the study site (Waterhouse et al., 2021), resulted in a maximum instantaneous light levels of $393 \mu \mathrm{mol}$ quanta $\mathrm{m}^{-2} \mathrm{~s}^{-1}$ (Figure 8A). At $10 \mathrm{~m}$ depth the maximum PAR level was $92 \mu \mathrm{mol}$ quanta $\mathrm{m}^{-2} \mathrm{~s}^{-1}$ (Figure 8A).

Considering the effect of SSCs, at $1.5 \mathrm{mg} \mathrm{L}^{-1}$ maximum instantaneous PAR levels decreased from $393 \mu$ mol quanta $\mathrm{m}^{-2}$ $\mathrm{s}^{-1}$ to $16 \mu \mathrm{mol}$ quanta $\mathrm{m}^{-2} \mathrm{~s}^{-1}$ at $10 \mathrm{mg} \mathrm{L}^{-1}$ (Figure 8A). The change in the spectral profiles and preferential loss of blue resulting from change in SSCs is shown as a shift of peak irradiance from $550 \mathrm{~nm}$ to $575 \mathrm{~nm}$ (Figure 8C) (see Figure 4D for empirical measurements of the spectral profile at $1 \mathrm{mg} \mathrm{L}^{-1}$ at $5 \mathrm{~m}$ depth).

Considering the effect of solar elevation, PAR levels at solar noon decreased $30 \%$ from $393 \mu \mathrm{mol}$ quanta $\mathrm{m}^{-2} \mathrm{~s}^{-1}$ at $0^{\circ}$ (the maximum elevation at solar noon in the summer time) to 274 $\mu$ mol quanta $\mathrm{m}^{-2} \mathrm{~s}^{-1}$ at $43^{\circ}$ (the lowest elevation at solar noon and occurs in the winter time) (inset graph in Figure 8B).

\section{Light Exposure Experiments}

The solar model was used to generate four light scenarios (S) including $6 \mathrm{~mol}$ quanta $\mathrm{m}^{2} \mathrm{~d}^{-1}$ and $1 \mathrm{~mol}$ quanta $\mathrm{m}^{2} \mathrm{~d}^{-1}$ PAR under either a broad spectrum peaking in the blue wavelengths (S1 and S2 in Figure 9A) or under a 'green-yellow-shifted' spectrum (S3 and S4 in Figure 9B). These spectra were then recreated in the aquarium and corals held for 28-d under the 4 different scenarios under a $12 \mathrm{~h} \mathrm{~L}: \mathrm{D}$ cycle of ascending and decreasing light level. The scenarios are shown as maximum (noon) instantaneous light and daily light integrals as PAR and also as PUR calculated using equation 1 in Figures 9A,B.

No mortality or partial mortality was observed in $P$. verrucosa over the experiment. Significant treatment effects were identified for growth rate and symbiont density (AICc $\omega$ i value of 1 and 0.95 , respectively (Table 1 ) with decreases in the lower light scenarios (S2 and S4) compared to the higher light treatments (S1 and S3). While the higher quantity of light clearly benefited growth, corals exposed to the high light, shifted spectrum scenario (S3) did not grow as much as those in the high light, normal spectra scenario (S1) and had reduced symbiont densities at the end of the exposure period (Figure 9).

Total Chl a concentrations were lowest in the low light treatments (S2 and S4), but also lower in the high light, shifted spectrum (S3) treatment (Figure 9). Conversely, the concentrations of $\mathrm{Chl}$ a per cell were highest at the two low light treatments (S2 and S4); however, no significant treatment effect was identified (AiCc $\omega$ i value 0.077, Table 1).

A significant variation in both the amount of total lipids and the ratio of storage to structural lipids was observed between the four light scenarios (Figure 9) although there was more evidence for a treatment effect with lipid ratios (AiCc $\omega$ i value of 0.877 vs. 0.667 , respectively). Interestingly, both lipid variables showed similar patterns between light treatments and were most impacted by the low light (S2 and S4) treatments with up to 2-fold decreases observed.

\section{DISCUSSION AND CONCLUSIONS}

Fine sediments in the water column scatter and absorb light reducing light availability for benthic photoautrophs. The elevated water turbidity (cloudiness) from enhanced sediment runoff from the land is considered a threat to coastal coral reefs and seagrass ecosystem (ISRS, 2004; GBRMPA, 2019, 2020). Despite concerns in the inshore turbid-zone reefs of the inner Great Barrier Reef dating back to the 1980s (Brodie et al., 2012), very few direct measurements of benthic light have been made there (but see Luter et al., 2021). In this study, spectral changes and preferential loss of more photosynthetically useful blue light was identified in the turbid plumes produced by a dredge, supporting earlier observations of Jones et al. (2016). The same changes were also identified during the natural windwave induced turbidity event using in situ multi-spectral sensor. In the turbid-zone coral reefs communities of the inner GBR sediment resuspension events are frequent (Larcombe et al., 1995, 2001; Orpin et al., 1999; Macdonald et al., 2013; Luter et al., 2021). Light reduction by suspended sediment involving shifts to longer, less photosynthetically useful wavelengths is therefore a common and previously unrecognised occurrence in the inshore turbid-zone reefs.

Light profiling in the blue-water environment outside of the turbid bay near the $20 \mathrm{~m}$ isobath showed the well-known depth related attenuation of red light resulting in a spectra peaking at $475 \mathrm{~nm}$ wavelength (Smith and Baker, 1981; Kirk, 2010). Inside the bay, profiles beside the reef showed similar attenuation of red light with depth but also attenuation of the shorter (blue) wavelengths with increasing depth. Light profiling through the sediment plumes caused by the dredging showed much more pronounced attenuation of the blue wavelengths proportional to suspended sediment concentration. The nett effect of the attenuation at both ends of the PAR spectrum was to monochromate the light with increasing depth, shifting the peak in the underwater spectrum $100 \mathrm{~nm}$ to the greenyellow waveband peaking at $>575 \mathrm{~nm}$. The shift is a well-known characteristic of turbid water (Van Duin et al., 2001; Mobley et al., 2004; Sundarabalan et al., 2016) and the loss of blue light is significant for corals as green-yellow light is poorly absorbed and hence less useful for photosynthesis (Morel, 1978, 1991). The implications are that sediment resuspension events in the inner GBR can result in a loss of light quantity and quality.

The preferential absorption of red light by pure seawater is well-known (Smith and Baker, 1981), as is the preferential absorption of the blue region which is usually attributed to humic-like and protein-like fluorophores of DOM (i.e., CDOM) produced by the decomposition of plant and animal matter (Bricaud et al., 1981; Jaffé et al., 2008; Hansell and Carlson, 2014; Jerlov, 2014). Known CDOM sources into Cleveland Bay include freshwater input from the many tributaries and creeks entering the bay (Blondeau-Patissier et al., 2009). CDOM sources also include autochthonous production from aquatic primary 


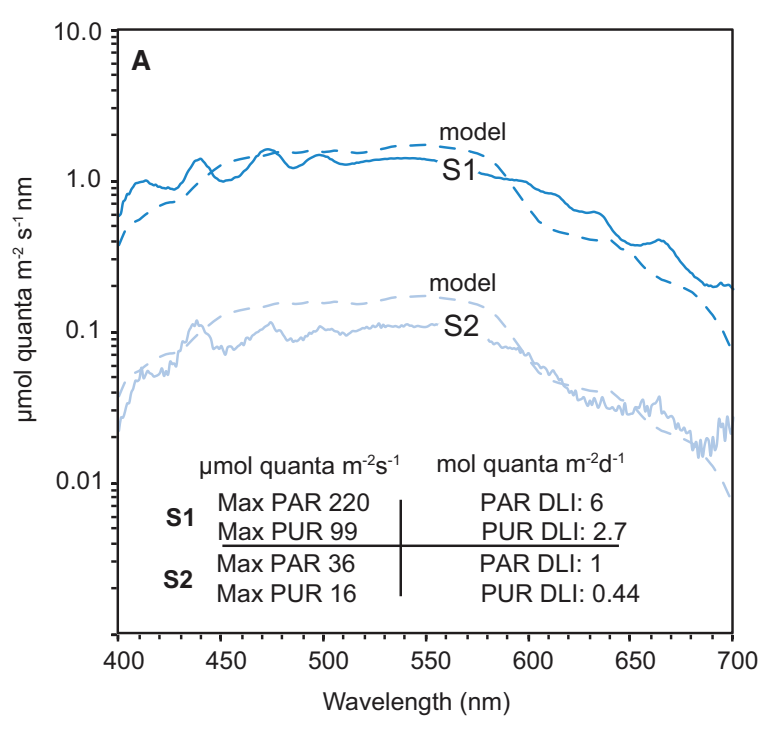

C Symbiont density $\left(\times 10^{6} \mathrm{~cm}^{-2}\right)$

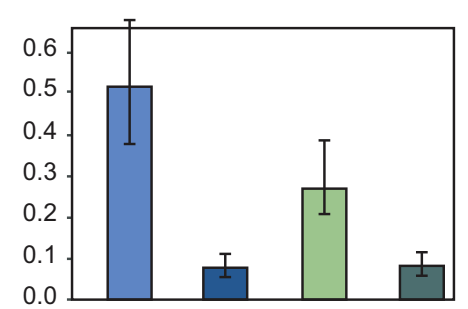

F \% Total lipid

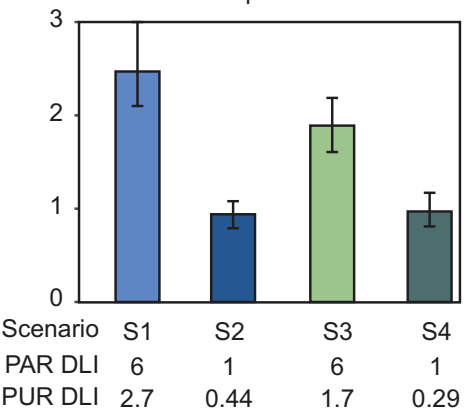

D pg Chl a cell-1

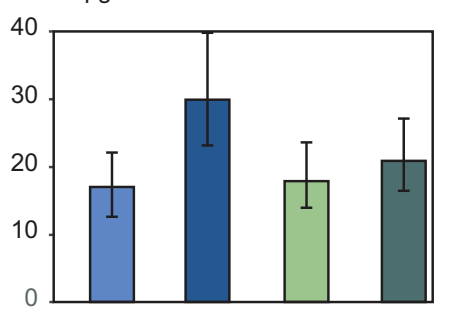

G Lipid storage:structural

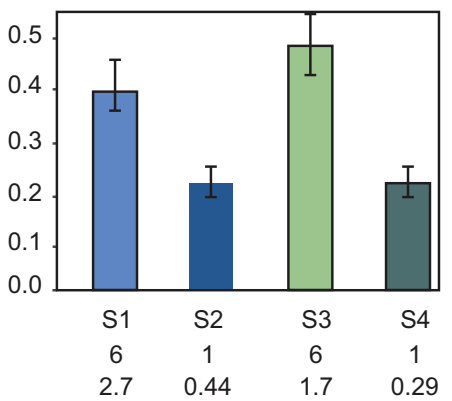

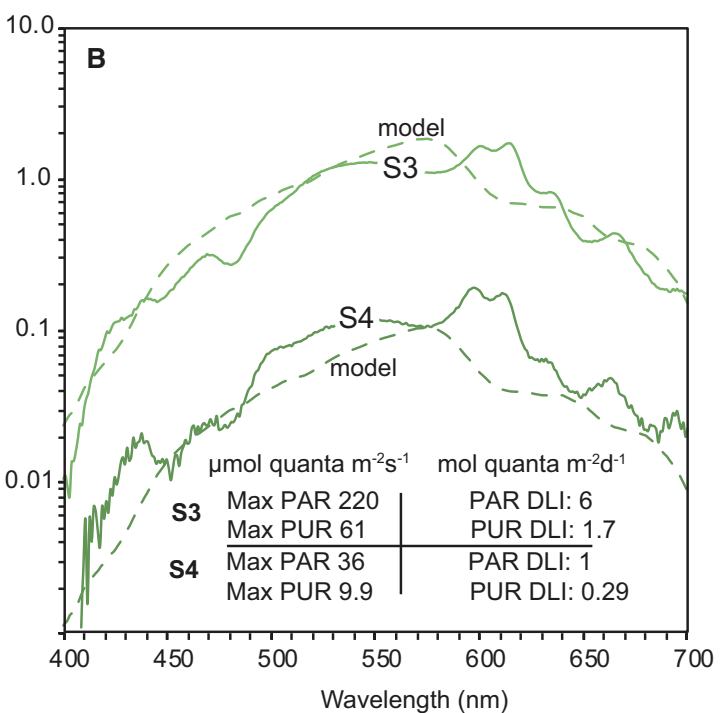

E Chl a mg cm-2

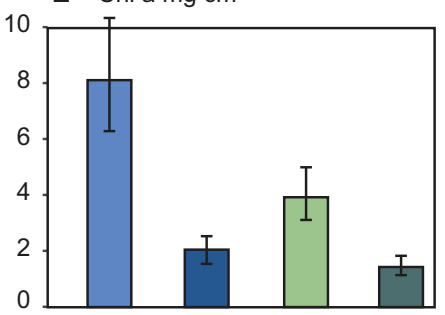

H Growth (\% of initial weight)

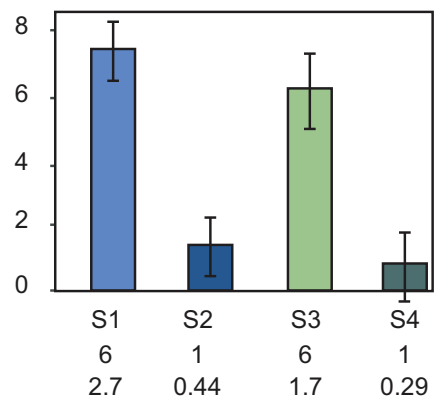

FIGURE 9 | (A,B) Modelled (dashed lines) and measured (solid lines) irradiance ( $\mu$ mol quanta $\mathrm{m}^{-2} \mathrm{~s}^{-1} \mathrm{~nm}^{-1}$ ) profiles during the 28 -d laboratory experiment with the coral Pocillopora verrucosa. The spectral profiles mimic light quantity and spectral quality at $5 \mathrm{~m}$ depth (cloud-free days) and a zenith angle of $19^{\circ}$ (at solar noon) derived from empirical solar irradiance model and correspond to light levels expected under SSCs of 0.5 and $10 \mathrm{mg} \mathrm{L}^{-1}$. Numbers in the figures represent the four light treatments used expressed as maximum (12 noon) PAR or PUR as $\mu$ mol quanta $\mathrm{m}^{-2} \mathrm{~s}^{-1}$, and daily light integral (mol quanta $\mathrm{m}^{2}$ ) from the sinusoidal ramping up and down over the $12 \mathrm{~h}$ light cycle, (C-H) Mean and 95\% confidence intervals for each response variable over the 4 light treatments.

producers such as reefs and seagrass beds (Carder et al., 1989; Hansell et al., 2002; Otis et al., 2004), and groundwater and porewater exchange (Webb et al., 2019). Mineral particles are more efficient in scattering light compared with other particulates such as phytoplankton because of their higher refractive indices (Bowers and Binding, 2006). One interpretation of the blue light attenuation signal with elevated SSCs, is that light scattering by mineral NAPs greatly increased the photon pathlength through the water column increasing the probability of absorption of blue light by CDOM (Kirk, 1976, 1985). Binding et al. (2008) have also suggested that the UV-blue absorption signatures could be due to electrochemical adsorption of CDOM onto the mineral surfaces (Wozniak and Dera, 2007).

A different explanation is that the UV-blue light absorption is related to the detrital material and/or to the sediments themselves and the elemental content of the mineral NAP. Babin et al. (2003b) and Babin and Stramski (2004) examined absorption characteristics of different particles of different mineralogical 
TABLE 1 | Relative model weights for P. verrucosa examining effects of 28 days of varied light scenario (S1-S4).

\begin{tabular}{|c|c|c|c|c|c|c|c|c|c|c|c|c|}
\hline & & & \multicolumn{2}{|c|}{ Symbiont density } & \multicolumn{5}{|c|}{ Pigments per cell } & & \multicolumn{2}{|c|}{ Pigments per $\mathrm{cm}^{2}$} \\
\hline $\operatorname{Tr}$ & & & \multicolumn{2}{|c|}{0.951} & \multicolumn{5}{|c|}{0.077} & & \multicolumn{2}{|c|}{0.988} \\
\hline Null & & & \multicolumn{2}{|c|}{0.049} & \multicolumn{5}{|c|}{0.923} & & \multicolumn{2}{|c|}{0.012} \\
\hline & & & \multicolumn{2}{|c|}{ Total lipids } & \multicolumn{5}{|c|}{ Lipid ratio } & & \multicolumn{2}{|c|}{ Buoyant Weight } \\
\hline $\operatorname{Tr}$ & & & \multicolumn{2}{|c|}{0.667} & \multicolumn{4}{|c|}{0.877} & & & \multicolumn{2}{|c|}{1} \\
\hline \multirow{2}{*}{ Null } & \multicolumn{4}{|c|}{ Symbiont density } & \multicolumn{4}{|c|}{ Pigments per cell } & \multicolumn{4}{|c|}{ Pigment per $\mathrm{cm}^{2}$} \\
\hline & S1 & S2 & S3 & S4 & S1 & S2 & S3 & S4 & S1 & S2 & S3 & S4 \\
\hline S1 & 1 & 0 & 0 & 0 & 1 & 0 & 0.39 & 0.15 & 1 & 0 & 0 & 0 \\
\hline S2 & 0 & 1 & 0 & 0.28 & 0 & 1 & 0 & 0.03 & 0 & 1 & 0 & 0.04 \\
\hline S4 & S1 & S2 & S3 & S4 & S1 & S2 & S3 & S4 & S1 & S2 & S3 & S4 \\
\hline S1 & 1 & 0 & 0 & 0.01 & 1 & 0 & 0 & 0 & 1 & 0 & 0.02 & 0 \\
\hline S2 & 0 & 1 & 0 & 0.46 & 0 & 1 & 0 & 0.39 & 0 & 1 & 0 & 0.21 \\
\hline S3 & 0 & 0 & 1 & 0.01 & 0 & 0 & 1 & 0 & 0.02 & 0 & 1 & 0 \\
\hline S4 & 0.01 & 0.46 & 0.01 & 1 & 0 & 0.39 & 0 & 1 & 0 & 0.21 & 0 & 1 \\
\hline
\end{tabular}

Model weights are based on AICC comparison between a model with the DLI treatment effect (DLI) and an intercept only "Null" model (Null). Post hoc comparisons were carried out using Bayesian posterior probability contrasts (calculated as the percentage overlap of posterior probabilities densities) between light scenario treatment pairs separately for each response variable.

and elemental composition. Absorption in the visible region was undetectable in pure samples, but blue-green absorption was much higher in sediments with a significant iron content (Babin and Stramski, 2004). The spectral signatures of coastal NAP samples are similar to the absorption spectra of iron oxides or hydroxides (Karickhoff and Bailey, 1973; Sherman and Waite, 1985). It was suggested that $\mathrm{Fe}^{+3}$ and $\mathrm{Fe}^{+2}$ cations on the particle surface or within the mineral lattice were responsible (Karickhoff and Bailey, 1973; Babin and Stramski, 2004; Stramski et al., 2007). Light absorption itself resulted from transfer of an electron from oxygen to iron, between iron and an adjacent cation or transfer to a higher energy orbital within the same iron atom (Babin and Stramski, 2004). The interpretation of iron oxide and hydroxide as the inorganic chromophorous agent of mineral NAPs was also supported by the study of Estapa et al. (2012) of mass-specific light absoption by particulate matter from the terrestrially influenced coast of Louisiana (US).

This explanation is consistent with known mineral distribution in sediments on the GBR. The inshore central regions are significantly influenced by terrigenous run off (Hopley et al., 2007), receiving siliciclastic and aluminosilicate clay and silts such as kaolinite, smectite and illite, and silicate sand from point-source fluvial inputs (Belperio, 1983; Belperio and Searle, 1988; Mathews et al., 2007). $\mathrm{Al}_{2} \mathrm{O}_{3}$ and $\mathrm{Fe}_{2} \mathrm{O}_{3}$ are the major constituents of such terrestrially-derived aluminosilicates or oxyhydroxides (Calvert and Pedersen, 1993) and often used as an indicator of terrigenously-derived sediments on the
GBR (Johns et al., 1994). Cleveland Bay is infilled with fluvial sediments from the Ross and Burdekin rivers (Carter et al., 1993) and total Fe content is high: $0.8-3.3 \%$ (Coomans and Brunskill, 2000), 0.8-4.8 \% (Reichelt and Jones, 1994) and up to $4-5 \%$ (Duckworth et al., 2017), consistent with other measurements of iron in inner GBR sediments (Alongi et al., 1993; Johns et al., 1994). The iron content of these sediments are orders of magnitude higher than the carbonate dominated biogenous mineral particles of the mid and outer shelf reefs (Passlow et al., 2005; Mathews et al., 2007; Duckworth et al., 2017).

The significance of the spectral changes under elevated SSCs is they shift the irradiance from photosynthetically useful to less useful wavelengths. In corals the symbiotic dinoflagellates (family Symbiodiniaceae, Lajeunesse et al., 2018) have two major light harvesting complexes, the water soluble peridinin-chlorophyll aprotein (PCP) complex and the membrane bound chl a chl $\mathrm{c}_{2}$ peridinin-protein complex (acpPC) (Prézelin and Haxo, 1976; Song et al., 1976; Iglesias-Prieto et al., 1991, 1993). The absorption peaks for the coral symbionts are in in the blue $(440-480 \mathrm{~nm}$ range) due to chlorophyll a, chlorophyll $c_{2}$ and carotenoids, and at $662 \mathrm{~nm}$ due to chlorophyll a (Halldal, 1968; Prézelin et al., 1976; Dustan, 1982; Kuhl et al., 1995; Levy et al., 2003; Hennige et al., 2009; Niedzwiedzki et al., 2014; Szabó et al., 2014; Wangpraseurt et al., 2014c). The absorption spectrum of Symbiodinium PCP is a broad band between $400-550 \mathrm{~nm}$ (Iglesias-Prieto et al., 1991; Iglesias-Prieto and Trench, 1994; Niedzwiedzki et al., 2014). PCP therefore extends the absorption 
profile into the blue green (see further below) but the absorption at $550-600 \mathrm{~nm}$ is still comparatively weak and this coincides with the peak wavelength of light transmission under elevated SSCs (see Figure 5A).

Morel (1978) first suggested weighting PAR according to usability in photosynthesis introducing the term photosynthetically usable radiation (PUR). The weighting is based on a photosynthetic action spectrum. Action and absorption spectra have been derived for Symbiodiniaceae from isolated and intact corals (Halldal, 1968; Scott and Jitts, 1977; Dustan, 1982; Schlichter and Fricke, 1991; Kuhl et al., 1995; Hennige et al., 2009; Wangpraseurt et al., 2014c). Action and absorption spectra are usually quite similar (Kirk, 2010) and in this study PUR calculations were based on the absorption spectra of isolated algal symbionts from in vivo cultures of multiple different Symbiodiniaceae clades (described in Hennige et al., 2009). The data indicates elevated SSCs can result in as much as 25\% decrease in the PUR:PAR as the result of the shift away from the main algal symbiont absorption bands. Functionally similar to the PUR:PAR ratio is the simpler blue to green ratio $(B / G, \lambda 455: 555 \mathrm{~nm})$ ratio used in this study. The decrease in underwater light levels caused by elevated SSCs was accompanied by a decrease in the ratio during the week-long turbidity event (Figure 3E), returning to background levels as the event decayed. In contrast, decreases in underwater light levels caused by clouds (without elevated SSCs) had no spectral effects indicating clouds tend to act more like neutral density filters (Morel, 1991). The implications are that periods of light reduction by turbidity vs. reduction by clouds can be readily identified by the spectral profile and blue green ratio at a site and depth. Such a diagnostic would be useful for contextualising and further understanding the risk of enhanced sediment run-off to the inshore turbid water communities and alleviate the need for a nearby dedicated above water PAR sensor to identify light reduction by clouds.

The empirical, spectral solar irradiance model developed from the wavelength specific light attenuation (constructed from the hyperspectral plume profiling study, Figure 5) accurately predicted benthic PAR measured with the multi-spectral sensor on the reef, using only information on suspended sediment concentration, depth and solar elevation angle (Figures 7C,D). Where improved model accuracy is required, the work of Gregg and Carder (1990) or other radiative transfer models such as MODTRAN (Berk et al., 1989) is recommended. The transmittance factor 0.965 (Morel and Antoine, 1994; Morel and Maritorena, 2001) used to correct for loss by reflection at the sea surface is wavelength independent. Although less suitable for low solar elevations and windy conditions as the transmission becomes more dependent on surface roughness (Austin, 1974; Preisendorfer and Mobley, 1986), the testing of modelled vs. measured data was conducted under clear skies and low wind and low zenith angles around solar noon. The measured surface light levels over the testing period aligned to the predicted surface irradiance from libRadtran for cloud free days; however, during partially cloudy noon periods surface levels were both below and above the predicted surface values. The lower values are intuitive and associated with clouds obscuring the path of the solar beam but the higher than predicted values are less so. We suggest these are examples of cloud enhancement (CE) or overirradiance or irradiance enhancement (Robinson, 1966; Nack and Green, 1974; Pfister et al., 2003; Gueymard, 2017). These cloud enhancement periods are associated with scattering from sides of clouds and strong forward Mie scattering within clouds of low optical depth (Yordanov et al., 2013; Pecenak et al., 2016; Gueymard, 2017). The enhancement periods of elevated light can last for seconds to several minutes and involve up to a 30-60\% increases in light (Yordanov et al., 2013, 2015; Almeida et al., 2014). The consequences of these short periods of overirradiance on coral physiology have not been explored. Cloud enhancement at seasonally high light levels could give rise to very high absolute light levels, which in combination with elevated seawater temperatures could result in or at least exacerbate coral bleaching in the photoinhibition model of bleaching (Jones et al., 1998; Hoegh-Guldberg, 1999; Jones and Hoegh-Guldberg, 2001). Interestingly, irrespective of CE effects, cloud seeding and cloud brightening to reduce light levels is currently being tested on the GBR as a local geoengineering solution to decrease solar heating and lower water temperatures to prevent bleaching (McDonald et al., 2019).

Given the success of the empirical, spectral solar irradiance model, the optical nomographs in Figure 8 was produced to graphically display the light levels corals experience in the turbidzone reefs of the GBR under a range of SSCs, solar elevation and depth conditions. The reefs around Magnetic Island and at Paluma Shoals (a nearshore turbid-zone reef complex $20 \mathrm{~km}$ west of Magnetic Island, Figure 1 inset) are known to have highly compressed depth distributions (Browne et al., 2010, 2012; Morgan et al., 2016; Ceccarelli et al., 2020) showing virtual loss of branching, tabular and corymbose corals by $\sim 5 \mathrm{~m}$ depth. Beyond this depth the corals become sparse and by $7 \mathrm{~m}$ are largely limited to isolated foliaceous, encrusting and massive growth forms (typically Turbinaria and Montipora spp) (Morgan et al., 2016). Using a scenario where the sun is directly overhead i.e., solar culmination and an angle of $0^{\circ}$ from vertical, and under an ambient background SSC of $1.5 \mathrm{mg} \mathrm{L}^{-1}$ (Waterhouse et al., 2021) the maximum instantaneous noon-time PAR at $5 \mathrm{~m}$ depth is $\sim 393 \mu \mathrm{mol}$ quanta $\mathrm{m}^{2} \mathrm{~s}^{-1}$, or $\sim 18 \%$ of light just under the water surface (estimated as 2,200 $\mu \mathrm{mol}$ quanta $\mathrm{m}^{2} \mathrm{~s}^{-1}$ ). At $7 \mathrm{~m}$ depth, which is effectively the lower limits for coral presence, the light was $10 \%$ of the maximum instantaneous noon-time. This light requirement of the corals in the inshore turbid reef zone communities is the same or slightly higher than minimum light requirement for seagrasses (Duarte, 1991; Dennison et al., 1993; Kenworthy and Fonseca, 1996) which are known to have high light requirements compared to many phytoplankton and macroalgae (1-5\% incident light) (Lee et al., 2007a).

The pocilloporid coral Pocillopora verrucosa was exposed for 28-d to a 6 or $1 \mathrm{~mol}$ quanta $\mathrm{m}^{2} \mathrm{~d}^{-1}$ light scenario (DLI), each under either a broad spectrum peaking in the blue wavelengths or green-yellow shifted spectrum, mimicking the effect of a $0.5 \mathrm{mg}$ $\mathrm{L}^{-1}$ or $10 \mathrm{mg} \mathrm{L}^{-1}$ SSC at a depth of $5 \mathrm{~m}$ (from the spectral solar irradiance model). A pocilloporid was chosen for the experiment as they regarded as light sensitive (Ziegler et al., 2014; PoquitaDu et al., 2019) and primarily phototrophic and with nutritional 
needs mostly met by photosynthesis (Wellington, 1982). They are one of the families common in high numbers in clear water on the Great Barrier Reef but restricted to less than a $2 \mathrm{~m}$ depth in more turbid settings (Thompson et al., 2018). In laboratory experiments Pocilloporids are sensitive to light reduction, losing their algal symbionts and discolouring or bleaching during low light periods (Bessell-Browne et al., 2017b; Jones et al., 2020; Luter et al., 2021). A DLI of $6 \mathrm{~mol}$ quanta $\mathrm{m}^{2}$ of PAR under a green-yellow shifted spectrum, resulted in a striking $50 \%$ loss of algal symbionts compared to the same PAR light level under the broad spectrum. Although PAR levels were the same between treatments $\left(6 \mathrm{~mol}\right.$ quanta $\left.\mathrm{m}^{2} \mathrm{~d}^{-1}\right)$, the PUR levels were $40 \%$ lower in the green-yellow light scenario. The low light scenario with a broad light spectrum resulted in an increase in the chlorophyll a concentration of the symbionts indicative of photoacclimation, but nevertheless significant decreases in algal symbiont density to $<15 \%$ of the higher light broad spectrum occurred. Growth, total lipids and the ratio of storage to structural lipids were also much lower. The lower light green spectrum scenario showed similar losses of the algal symbionts although the photoacclimatory increase in Cha per algal cell in the low light broad spectrum was not observed and Chl a per $\mathrm{cm}^{2}$ was significantly different between the two low light treatments.

Similar changes in response to reduced quantity of light from turbidity have been described previously for a range of coral species (Bessell-Browne et al., 2017a,b; Jones et al., 2020; Luter et al., 2021) and the cue for the dissociation of the symbiosis was suggested to be a reduction in translocation of algal-derived photosynthate to the host. The response to the modified quality of light from turbidity has not been described before and emphasises the need to justify and describe the spectrum of artificial light sources used in future laboratory based studies of coral physiology (see also Wangpraseurt et al., 2014c; Luter et al., 2021). These results are preliminary as they are limited to a single species but nevertheless the $50 \%$ loss of algal symbionts by the spectral modification and shift from a broad spectrum to greenish light was a strong response. Although the absolute level of light is important, the spectral changes to less photosynthetically useful wavelengths under elevated turbidity also reduces the availability of PAR.

The spectral changes under elevated turbidity are potentially also significant with respect to coral bleaching and the climate change refugia hypothesis of turbid nearshore reefs (Van Woesik et al., 2012). The preliminary experiments of Fitt and Warner (1995) showed that high energy blue light promotes bleaching in cultured algal symbionts. If follows that the preferential attention of higher energy blue light by turbidity and elevated SSCs may also ameliorate the physiological stress to the symbiosis associated with light during a marine heatwave (Sully and Van Woesik, 2020 and references therein). For both an underabundance and overabundance of light in turbid water coral communities, both spectral changes as well as total light availability needs to be considered.

The corals dinoflagellate symbionts (family Symbiodiniaceae) containing peridinin as an accessory pigment (Iglesias-Prieto et al., 1991, 1993) which harvests green wavelengths (470$550 \mathrm{~nm}$ ) where chlorophyll absorbs very poorly (Polívka et al.,
2007). Because of the very high efficiency of Per-Chl-a excitation energy transfer (Song et al., 1976; Carbonera et al., 2014) green wavelengths can still be used for photochemistry albeit much less effectively. This theoretically should lessen the impacts of the spectral changes although clearly not sufficiently enough in the experiment. Further studies of the effects of spectral shifts to yellow-green wavelengths and the use of PUR are recommended, but also need to consider the very different light climate in the intact symbiosis (in symbio) which are known to be substantially different from the ambient incident underwater irradiance regime. Light levels in the tissue can be enhanced from multiple scattering of photons and diffuse back scattering by the aragonite skeleton (Kuhl et al., 1995; Enriquez et al., 2005; Brodersen et al., 2014). Host pigments can also scatter, reflect and absorb and remit light (Schlichter et al., 1986; Salih et al., 2000; Dove et al., 2001; Gilmore et al., 2003; D’Angelo et al., 2008; Smith et al., 2017) and so the optical properties of the host tissue strongly effects light use efficiency with rapid attenuation and spectrally dependent changes (Kuhl et al., 1995; Wangpraseurt et al., 2012, 2014a,b; Szabó et al., 2014; Lichtenberg et al., 2016).

The inner GBR turbid zone reef communities routinely experience natural wind and wave induced resuspension events and hence periods of reduced light levels and, as shown in this study, changes in the underwater light spectrum. The potential threat to these reefs by enhanced sediment run off from the land is well-recognised and changes in light availability to benthic photoautrophs one of the primary cause effect pathways (GBRMPA, 2019, 2020). However, suprisingly few in situ irradiance intensity measurements have ever been made there (Luter et al., 2021). This seems an omission and the technology is now available to transition to affordable and calibratable in situ multi-spectral light measurements and define the light environment in absolute terms of irradiance intensity-for example DLIs over different periods of time and at different depths (Luter et al., 2021). As shown in the present study, multi-spectral sensors can also allow the partitioning of light reduction by clouds and sediment resuspension providing additional information for a risk assessment of enhanced sediment runoff.

In addition to absorption by CDOM and chlorophyll, the preferential absorption of blue light by NAPS (detrital and mineral) is another potential cause of the green hue of naturally turbid coastal reefs as seen underwater. Similarly, as seen from above, Bowers and Binding (2006) noted moderately turbid seas look green, an effect which is often attributed to algal blooms but could also be attributed to the blue light absorption of low levels of NAPs coupled to red light absorption of water (Claustre et al., 2002). Such an effect may also contribute to the green colouration of river plumes once entering the coastal GBR as seen from ocean colour satellites (Devlin et al., 2012, 2015; Petus et al., 2018).

\section{DATA AVAILABILITY STATEMENT}

The raw data supporting the conclusions of this article will be made available by the authors, without undue reservation. 


\section{AUTHOR CONTRIBUTIONS}

RJ: conception and wrote the first draft. M-CP, HL, RF, and RJ: experimental design. M-CP and HL: conducting the experiments. M-CP, HL, RF, RJ, WK, and MS: data processing and analysis and contributed to writing, reviewing, and editing. RF and HL: statistical analyses. DF: lipid analysis. All authors approved the manuscript for submission.

\section{FUNDING}

This project was funded by the Australian Government's National Environmental Science Programme (NESP Project 2.1.9) to RJ and RF, co-investment by the Australian Institute of Marine

\section{REFERENCES}

AIMS (2020). Australian Institute of Marine Science. Northern Australia Automated Marine Weather and Oceanographic Stations, Sites: (Cleveland Bay), Parameters: (Light). doi: 10.25845/5c09bf93f315d

Almeida, M. P., Zilles, R., and Lorenzo, E. (2014). Extreme overirradiance events in São Paulo, Brazil. Solar Energy 110, 168-173. doi: 10.1016/j.solener.2014.09.012

Alongi, D. M., Tirendi, F., and Christoffersen, P. (1993). Sedimentary profiles and sediment-water solute exchange of iron and manganese in reef- and river-dominated shelf regions of the Coral Sea. Cont. Shelf Res. 13, 287-305. doi: 10.1016/0278-4343(93)90111-A

Anthony, K., Ridd, P., Orpin, A., Larcombe, P., and Lough, J. (2004). Temporal variation of light availability in coastal benthic habitats: effects of clouds, turbidity, and tides. Limnol. Oceanogr. 49, 2201-2211. doi: 10.4319/lo.2004.49.6.2201

Antoine, D., Schroeder, T., Slivkoff, M., Klonowski, W., Doblin, W., Lovell, J., et al. (2017). The IMOS Radiometery Task Team. Final Report. Hobart, TAS: Integrated Marine Observing System (IMOS). Available online at: http://imos. org.au/facilities/task-teams/radiometry/

Austin, R. (1974). "The remote sensing of spectral radiance from below the ocean surface," in Optical Aspects of Oceanography, eds N. G. Jerlov and E. S. Nielsen (San Diego, CA: Academic), 317-344.

Babin, M., Morel, A., Fournier-Sicre, V., Fell, F., and Stramski, D. (2003a). Light scattering properties of marine particles in coastal and open ocean waters as related to the particle mass concentration. Limnol. Oceanogr. 48, 843-859. doi: $10.4319 / \mathrm{lo} .2003 .48 .2 .0843$

Babin, M., and Stramski, D. (2002). Light absorption by aquatic particles in the near-infrared spectral region. Limnol. Oceanogr. 47, 911-915. doi: 10.4319/lo.2002.47.3.0911

Babin, M., and Stramski, D. (2004). Variations in the mass-specific absorption coefficient of mineral particles suspended in water. Limnol. Oceanogr. 49, 756-767. doi: 10.4319/lo.2004.49.3.0756

Babin, M., Stramski, D., Ferrari, G. M., Claustre, H., Bricaud, A., Obolensky, G., et al. (2003b). Variations in the light absorption coefficients of phytoplankton, nonalgal particles, and dissolved organic matter in coastal waters around Europe. J. Geophysic. Res. Oceans 108:882. doi: 10.1029/2001JC000882

Bainbridge, Z., Wolanski, E., Alvarez-Romero, J., Lewis, S., and Brodie, J. (2012). Fine sediment and nutrient dynamics related to particle size and floc formation in a Burdekin River flood plume, Australia. Mar. Pollut. Bull. 65, 236-248. doi: 10.1016/j.marpolbul.2012.01.043

Bates, D., Mächler, M., Bolker, B., and Walker, S. (2015). Fitting linear mixedeffects models using lme4. 67:48. doi: 10.18637/jss.v067.i01

Belperio, A. (1983). Terrigenous sedimentation in the central Great Barrier Reef lagoon: a model from the Burdekin region. BMR J. Austr. Geol. Geophys. 8, 179-190.

Belperio, A., and Searle, D. (1988). "Terrigenous and carbonate sedimentation in the Great Barrier Reef province," in Carbonate -Clastic Transitions.
Science, In Situ Marine Optics and the Port of Townsville Limited (POTL).

\section{ACKNOWLEDGMENTS}

We thank the Port of Townsville Limited (POTL) for provision of a boat and crew for the field work and permitting close access to the dredge for sampling; Matt Salmon, Craig Humphrey, Andrea Severati, Paul Boyd, and Eduardo Arias for design of the lighting systems; Manuel Nunez for the libRadtran calculations and QA/QC of the surface light measurements; and Leslie Clements for her help with pigment analyses.

Developments in Sedimentology, eds. L. J. Doyle and H. H. Roberts (Amsterdam: Elsevier), 42, 143-174.

Berk, A., Bernstein, L., and Robertson, D. (1989). MODTRAN: A Moderate Resolution Model for LOWTRAN7. GL-TR-89-0122, Air Force Geophysics Lab, Hanscom AFB.

Bessell-Browne, P., Negri, A. P., Fisher, R., Clode, P. L., Duckworth, A., and Jones, R. (2017a). Impacts of turbidity on corals: the relative importance of light limitation and suspended sediments. Mar. Pollut. Bull. 117, 161-170. doi: 10.1016/j.marpolbul.2017.01.050

Bessell-Browne, P., Negri, A. P., Fisher, R., Clode, P. L., and Jones, R. (2017b). Impacts of light limitation on corals and crustose coralline algae. Sci. Rep. 7:11553. doi: 10.1038/s41598-017-11783-Z

Binding, C. E., Jerome, J. H., Bukata, R. P., and Booty, W. G. (2008). Spectral absorption properties of dissolved and particulate matter in Lake Erie. Remote Sens. Environ. 112, 1702-1711. doi: 10.1016/j.rse.2007.08.017

Blondeau-Patissier, D., Brando, V. E., Oubelkheir, K., Dekker, A. G., Clementson, L. A., and Daniel, P. (2009). Bio-optical variability of the absorption and scattering properties of the Queensland inshore and reef waters, Australia. J. Geophys. Res. Oceans 114:C5. doi: 10.1029/2008JC005039

Bowers, D. G., and Binding, C. E. (2006). The optical properties of mineral suspended particles: a review and synthesis. Estuar. Coast. Shelf Sci. 67, 219-230. doi: 10.1016/j.ecss.2005.11.010

Brandon, R., Dierssen, H., and Hochberg, E. (2019). Water column optical properties of pacific coral reefs across geomorphic zones and in comparison to offshore waters. Rem. Sens. 11:1757. doi: 10.3390/rs11151757

Bricaud, A., Morel, A., and Prieur, L. (1981). Absorption by dissolved organic matter of the sea (yellow substance) in the UV and visible domains. Limnol. Oceanogr. 26, 43-53. doi: 10.4319/lo.1981.26.1.0043

Brodersen, K., Lichtenberg, M., Ralph, P., Kühl, M., and Wangpraseurt, D. (2014). Radiative energy budget reveals high photosynthetic efficiency in symbiontbearing corals. J. R. Soc. Interface 11:20130997. doi: 10.1098/rsif.2013.0997

Brodie, J., Kroon, F., Schaffelke, B., Wolanski, E., Lewis, S., Devlin, M., et al. (2012). Terrestrial pollutant runoff to the Great Barrier Reef: an update of issues, priorities and management responses. Mar. Pollut. Bull. 65, 81-100. doi: 10.1016/j.marpolbul.2011.12.012

Browne, N. K., Smithers, S. G., and Perry, C. T. (2010). Geomorphology and community structure of Middle Reef, central Great Barrier Reef, Australia: an inner-shelf turbid zone reef subject to episodic mortality events. Coral Reefs 29, 683-689. doi: 10.1007/s00338-010-0640-3

Browne, N. K., Smithers, S. G., and Perry, C. T. (2012). Coral reefs of the turbid inner-shelf of the Great Barrier Reef, Australia: an environmental and geomorphic perspective on their occurrence, composition and growth. Earth Sci. Rev. 115, 1-20. doi: 10.1016/j.earscirev.2012.06.006

Browne, N. K., Smithers, S. G., and Perry, C. T. (2013). Spatial and temporal variations in turbidity on two inshore turbid reefs on the Great Barrier Reef, Australia. Coral Reefs 32, 195-210. doi: 10.1007/s00338-012-0 965-1 
Bull, G. (1982). Scleractinian coral communities of two inshore high island fringing reefs at Magnetic Island, North Queensland. Mar. Ecol. Progr. Ser. Oldendorf 7, 267-277. doi: 10.3354/meps007267

Burnham, K. P., and Anderson, D. R. (2002). Model Selection and Multimodel Inference: A Practical Information-Theoretic Approach. New York, NY: Springer.

Cacciapaglia, C., and Van Woesik, R. (2016). Climate-Change Refugia: shading reef corals by turbidity. Glob. Change Biol. 22, 1145-1154. doi: 10.1111/gcb.13166

Calvert, S. E., and Pedersen, T. F. (1993). Geochemistry of recent oxic and anoxic marine sediments: implications for the geological record. Mar. Geol. 113, 67-88. doi: 10.1016/0025-3227(93)90150-T

Carbonera, D., Di Valentin, M., Spezia, R., and Mezzetti, A. (2014). The unique photophysical properties of the Peridinin-chlorophyll- $\alpha$-protein. Curr. Prot. Pept. Sci. 15, 332-350. doi: 10.2174/1389203715666140327111139

Carder, K. L., Steward, R. G., Harvey, G. R., and Ortner, P. B. (1989). Marine humic and fulvic acids: their effects on remote sensing of ocean chlorophyll. Limnol. Oceanogr. 34, 68-81. doi: 10.4319/lo.1989.34.1.0068

Carter, R., Johnson, D., and Hooper, K. (1993). Episodic post-glacial sea-level rise and the sedimentary evolution of a tropical continental embayment (Cleveland Bay, Great Barrier Reef shelf, Australia). Austr. J. Earth Sci. 40, 229-255. doi: 10.1080/08120099308728077

Ceccarelli, D. M., Evans, R. D., Logan, M., Mantel, P., Puotinen, M., Petus, C., et al. (2020). Long-term dynamics and drivers of coral and macroalgal cover on inshore reefs of the Great Barrier Reef Marine Park. Ecol. Appl. 30:e02008. doi: 10.1002/eap.2008

Claustre, H., Morel, A., Hooker, S. B., Babin, M., Antoine, D., Oubelkheir, K., et al. (2002). Is desert dust making oligotrophic waters greener? Geophys. Res. Lett. 29, 107-101. doi: 10.1029/2001GL014056

Clementson, L. (2013). “The CSIRO Method," in The Fifth SeaWiFS HPLC Analysis Round-Robin Experiment (SeaHARRE-5) NASA Technical Memorandum 2012217503, eds S. Hooker, L. Clementson, C. Thomas, L. Schlüter, M. Allerup, J. Ras, et al. Greenbelt, MD: NASA Goddard Space Flight Center.

Conlan, J. A., Rocker, M. M., and Francis, D. S. (2017). A comparison of two common sample preparation techniques for lipid and fatty acid analysis in three different coral morphotypes reveals quantitative and qualitative differences PeerJ 5:e3645. doi: 10.7717/peerj.3645

Coomans, D., and Brunskill, G. J. (2000). Modelling natural and enhanced trace metal concentrations in sediments of Cleveland Bay, Australia. Mar. Freshw. Res. 51, 739-747. doi: 10.1071/MF98141

D’Angelo, C., Denzel, A., Vogt, A., Matz, M. V., Oswald, F., Salih, A., et al. (2008). Blue light regulation of host pigment in reef-building corals. Mar. Ecol. Prog. Ser. 364, 97-106. doi: 10.3354/meps07588

Delandmeter, P., Lewis, S., Lambrechts, J., Deleersnijder, E., Legat, V., and Wolanski, E. (2015). The transport and fate of riverine fine sediment exported to a semi-open system. Estuar. Coast. Shelf Sci. 167, 336-346. doi: $10.1016 /$ j.ecss.2015.10.011

Dennison, W. C., Orth, R. J., Moore, K. A., Stevenson, J. C., Carter, V., Kollar, S., et al. (1993). Assessing water quality with submersed aquatic vegetation. Bioscience 43, 86-94. doi: 10.2307/1311969

Devlin, M. J., Mckinna, L. W., Álvarez-Romero, J. G., Petus, C., Abott, B., Harkness, P., et al. (2012). Mapping the pollutants in surface riverine flood plume waters in the Great Barrier Reef, Australia. Mar. Pollut. Bull. 65, 224-235. doi: 10.1016/j.marpolbul.2012.03.001

Devlin, M. J., Petus, C., Da Silva, E., Tracey, D., Wolff, N. H., Waterhouse, J., et al. (2015). Water quality and river plume monitoring in the great barrier reef: an overview of methods based on ocean colour satellite data. Rem. Sens. 7, 12909-12941. doi: 10.3390/rs71012909

Dove, S. G., Hoegh-Guldberg, O., and Ranganathan, S. (2001). Major colour patterns of reef-building corals are due to a family of GFP-like proteins. Coral Reefs 19, 197-204. doi: 10.1007/PL00006956

Duarte, C. M. (1991). Seagrass depth limits. Aquat. Bot. 40, 363-377. doi: 10.1016/0304-3770(91)90081-F

Duarte, C. M., August, S., Satta, M. P., and Vaque, D. (1998). Partitioning particulate light absorption: a budget for a Mediterranean Bay. Limnol. Oceanogr. 43, 236-244. doi: 10.4319/lo.1998.43.2.0236

Dubinsky, Z., and Falkowski, P. (2011). "Light as a source of information and energy in zooxanthellate corals," in Coral Reefs: An Ecosystem in Transition, eds Z. Dubinsky and N. Stambler (Dordrecht: Springer Netherlands), 107-118.
Duckworth, A., Giofre, N., and Jones, R. (2017). Coral morphology and sedimentation. Mar. Pollut. Bull. 125, 289-300. doi: 10.1016/j.marpolbul.2017.08.036

Dunne, R., and Brown, B. (1996). Penetration of solar UVB radiation in shallow tropical waters and its potential biological effects on coral reefs; results from the central Indian Ocean and Andaman Sea. Mar. Ecol. Prog. Ser. 144, 109-118. doi: 10.3354/meps144109

Dustan, P. (1982). Depth-dependent photoadaption by zooxanthellae of the reef coral Montastrea annularis. Mar. Biol. 68, 253-264. doi: 10.1007/BF00409592

Edmunds, P. J., Tsounis, G., Boulon, R., and Bramanti, L. (2018). Longterm variation in light intensity on a coral reef. Coral Reefs 37, 955-965. doi: 10.1007/s00338-018-1721-y

Emde, C., Buras-Schnell, R., Kylling, A., Mayer, B., Gasteiger, J., Hamann, U., et al. (2016). The libRadtran software package for radiative transfer calculations (version 2.0.1). Geosci. Model Dev. 9, 1647-1672. doi: 10.5194/gmd-9-1647-2016

Enriquez, S., Méndez, E. R., and Iglesias-Prieto, R. (2005). Multiple scattering on coral skeletons enhances light absorption by symbiotic algae. Limnol. Oceanogr. 50, 1025-1032. doi: 10.4319/lo.2005.50.4.1025

Estapa, M. L., Boss, E., Mayer, L. M., and Roesler, C. S. (2012). Role of iron and organic carbon in mass-specific light absorption by particulate matter from Louisiana coastal waters. Limnol. Oceanogr. 57, 97-112. doi: 10.4319/lo.2012.57.1.0097

Falkowski, P., Jokiel, P., and Kinzie, R. (1990). "Irradiance and corals," in Ecosystems of the World, ed Z. Dubinksy (Amsterdam: Elsevier), 89-107.

Falkowski, P. G., and Raven, J. A. (2013). Aquatic Photosynthesis. Princeton, NJ: Princeton University Press.

Fearns, P., Dorji, P., Broomhall, M., Chedzey, H., Symonds, G., Mortimer, N., et al. (2019). Plume Characterisation-Field Studies. Report of Theme 3-Project 3.2.1, Prepared for the Dredging Science Node. Perth, WA: Western Australian Marine Science Institution. Available online at: https://www.wamsi.org.au/ dredging-science-node/dsn-reports

Fisher, R., Bessell-Browne, P., and Jones, R. (2019). Synergistic and antagonistic impacts of suspended sediments and thermal stress on corals. Nat. Commun. 10:2346. doi: 10.1038/s41467-019-10288-9

Fisher, R., Stark, C., Ridd, P., and Jones, R. (2015). Spatial patterns in water quality changes during dredging in tropical environments. PLOS ONE 10:e0143309. doi: 10.1371/journal.pone.0143309

Fitt, W., and Warner, M. (1995). Bleaching patterns of four species of Caribbean reef corals. Biol. Bull. 189, 298-307.

Gallegos, C. L., Kenworthy, W. J., Biber, P. D., and Wolfe, B. S. (2009). Underwater spectral energy distribution and seagrass depth limits along an optical water quality gradient. Smithson. Contrib. Mar. Sci. 38, 359-367.

Gattuso, J.-P., Gentili, B., Duarte, C. M., Kleypas, J. A., Middelburg, J. J., and Antoine, D. (2006). Light availability in the coastal ocean: impact on the distribution of benthic photosynthetic organisms and their contribution to primary production. Biogeosciences 3, 489-513. doi: 10.5194/bg-3-4892006

GBRMPA (2019). Great Barrier Reef Outlook Report 2019. Great Barrier Reef Marine Park Authority, Townsville, QLD. Available online at: http://hdl.handle. net/11017/3474

GBRMPA (2020). Great Barrier Reef Marine Park Authority. Position Statement. Water Quality. Document No: 100516 Revision: 0 Date: 27-Oct-2020.

Gilmore, A. M., Larkum, A. W. D., Salih, A., Itoh, S., Shibata, Y., Bena, C., et al. (2003). Simultaneous time resolution of the emission spectra of fluorescent proteins and zooxanthellar chlorophyll in reef-building corals. Photochem. Photobiol. 77, 515-523. doi: 10.1562/0031-8655(2003)077andlt;0515:STROTEandgt;2.0.CO;2

Goreau, T. F. (1959). The ecology of Jamaican coral reefs I. Species composition and zonation. Ecology 40, 67-90. doi: 10.2307/1929924

Goreau, T. F., and Wells, J. (1967). The shallow-water Scleractinia of Jamaica: revised list of species and their vertical distribution range. Bull. Mar. Sci. $17,442-453$.

Gregg, W. W., and Carder, K. L. (1990). A simple spectral solar irradiance model for cloudless maritime atmospheres. Limnol. Oceanogr. 35, 1657-1675. doi: 10.4319/lo.1990.35.8.1657

Guest, J. R., Baird, A. H., Maynard, J. A., Muttaqin, E., Edwards, A. J., Campbell, S. J., et al. (2012). Contrasting patterns of coral bleaching susceptibility in 
2010 suggest an adaptive response to thermal stress. PloS ONE 7:e33353. doi: 10.1371/journal.pone.0033353

Guest, J. R., Low, J., Tun, K., Wilson, B., Ng, C., Raingeard, D., et al. (2016). Coral community response to bleaching on a highly disturbed reef. Sci. Rep. 6:20717. doi: $10.1038 /$ srep20717

Gueymard, C. A. (2017). Cloud and Albedo enhancement impacts on solar irradiance using high-frequency measurements from thermopile and photodiode radiometers. Part 1: impacts on global horizontal irradiance. Solar Energy 153, 755-765. doi: 10.1016/j.solener.2017.05.004

Halldal, P. (1968). Photosynthetic capacities and photosynthetic action spectra of endozoic algae of the massive coral Favia. Biol. Bull. 134, 411-424. doi: $10.2307 / 1539860$

Hansell, D. A., and Carlson, C. A. (2002). Biogeochemistry of Marine Dissolved Organic Matter. Cambridge, MA: Academic Press.

Hansell, D. A., and Carlson, C. A. (2014). Biogeochemistry of Marine Dissolved Organic Matter. Cambridge, MA: Academic Press.

Hansell, D. A., Carlson, C. A., and Carlson, C. A. (2002). Biogeochemistry of Marine Dissolved Organic Matter. San Diego, CA: Elsevier Science and Technology.

Hennige, S. J., Suggett, D. J., Warner, M. E., Mcdougall, K. E., and Smith, D. J. (2009). Photobiology of Symbiodinium revisited: bio-physical and bio-optical signatures. Coral Reefs 28, 179-195. doi: 10.1007/s00338-008-0444-x

Hochberg, E. J., Peltier, S. A., and Maritorena, S. (2020). Trends and variability in spectral diffuse attenuation of coral reef waters. Coral Reefs 39, 1377-1389. doi: 10.1007/s00338-020-01971-1

Hoegh-Guldberg, O. (1999). Climate change, coral bleaching and the future of the world's coral reefs. Mar. Freshw. Res. 50, 839-866. doi: 10.1071/MF99078

Hopley, D. (1982). The Geomorphology of the Great Barrier Reef. New York, NY: Wiley.

Hopley, D., Smithers, S. G., and Parnell, K. (2007). The Geomorphology of the Great Barrier Reef: Development, Diversity and Change. Cambridge: Cambridge University Press.

Houlbrèque, F., and Ferrier-Pagès, C. (2009). Heterotrophy in tropical scleractinian corals. Biol. Rev. Camb. Philos. Soc. 84, 1-17. doi: 10.1111/j.1469-185X.2008.00058.x

Huston, M. (1985). Patterns of species diversity on coral reefs. Annu. Rev. Ecol. Syst. 16, 149-177. doi: 10.1146/annurev.es.16.110185.001053

Iglesias-Prieto, R., Govind, N., and Trench, R. (1993). Isolation and characterization of three membranebound chlorophyll-protein complexes from four dinoflagellate species. Philosophic. Trans. R. Soc. Lond. Ser. B Biol. Sci. 340, 381-392. doi: 10.1098/rstb.1993.0080

Iglesias-Prieto, R., Govind, N. S., and Trench, R. K. (1991). Apoprotein composition and spectroscopic characterization of the water-soluble peridinin-Chlorophyll a-proteins from three symbiotic dinoflagellates. Proc. R. Soc. Lond. Ser. B Biol. Sci. 246, 275-283. doi: 10.1098/rspb.199 1.0155

Iglesias-Prieto, R., and Trench, R. K. (1994). Acclimation and adaptation to irradiance in symbiotic dinoflagellates.I. Responses of the photosynthetic unit to change in photon flux density. Mar. Ecol. Progr. Ser. 113, 163-175. doi: $10.3354 /$ meps 113163

IOCCG (2000). Remote Sensing of Ocean Colour in Coastal, and Other OpticallyComplex, Waters. Dartmouth, NS.

ISRS (2004). "The effects of terrestrial runoff of sediments, nutrients and other pollutants on coral reefs," in ISRS Briefing Paper 3 (International Society for Reef Studies).

Jaffé, R., Mcknight, D., Maie, N., Cory, R., Mcdowell, W., and Campbell, J. (2008). Spatial and temporal variations in DOM composition in ecosystems: the importance of long-term monitoring of optical properties. J. Geophys. Res. Biogeosci. 68:113. doi: 10.1029/2008JG000683

Jerlov, N. G. (1976). Marine Optics. Amsterdam: Elsevier.

Jerlov, N. G. (2014). Optical Oceanography. Amsterdam: Elsevier.

Johns, R. B., Brady, B. A., Butler, M. S., Dembitsky, V. M., and Smith, J. D. (1994). Organic geochemical and geochemical studies of Inner Great Barrier Reef sediments-IV. identification of terrigenous and marine sourced inputs. Organ. Geochem. 21, 1027-1035. doi: 10.1016/0146-6380(94)90 066-3

Jones, R., Bessell-Browne, P., Fisher, R., Klonowski, W., and Slivkoff, M. (2016). Assessing the impacts of sediments from dredging on corals. Mar. Pollut. Bull. 102, 9-29. doi: 10.1016/j.marpolbul.2015.10.049
Jones, R., Fisher, R., Stark, C., and Ridd, P. (2015). Temporal patterns in water quality from dredging in tropical environments. PLOS ONE 10:e0137112. doi: 10.1371/journal.pone.0137112

Jones, R., Giofre, N., Luter, H. M., Neoh, T. L., Fisher, R., and Duckworth, A. (2020). Responses of corals to chronic turbidity. Sci. Rep. 10:4762. doi: 10.1038/s41598-020-61712-w

Jones, R., and Hoegh-Guldberg, O. (2001). Diurnal changes in the photochemical efficiency of the symbiotic dinoflagellates (Dinophyceae) of corals: photoprotection, photoinactivation and the relationship to coral bleaching. Plant Cell Environ. 24, 89-99. doi: 10.1046/j.1365-3040.2001.00648.x

Jones, R., Hoegh-Guldberg, O., Larkum, A., and Schreiber, U. (1998). Temperature-induced bleaching of corals begins with impairment of the $\mathrm{CO}_{2}$ fixation mechanism in zooxanthellae. Plant Cell Environ. 21, 1219-1230. doi: 10.1046/j.1365-3040.1998.00345.x

Kahng, S. E., Akkaynak, D., Shlesinger, T., Hochberg, E. J., Wiedenmann, J., Tamir, R., et al. (2019). "Light, temperature, photosynthesis, heterotrophy, and the lower depth limits of mesophotic coral ecosystems," in Mesophotic Coral Ecosystems, eds Y. Loya, K. A. Puglise and T. C. L. Bridge (New York, NY: Springer), 801-828.

Kaly, U. L., Mapstone, B. D., Ayling, A. M., and Choat, J. H. (1994). "Coral Communities," in Townsville Port Authority Capital Dredging Works 1993: Environmental Monitoring Program, eds L. Benson, P. Goldsworthy, I. Butler, and J. Oliver (Townsville, QLD: Townsville Port Authority), 55-87.

Karickhoff, S. W., and Bailey, G. W. (1973). Optical absorption spectra of clay minerals. Clays Clay Miner. 21, 59-70. doi: 10.1346/CCMN.1973.0210109

Kenworthy, W. J., and Fonseca, M. S. (1996). Light requirements of Seagrasses Halodule wrightii and Syringodium filiforme derived from the relationship between diffuse light attenuation and maximum depth distribution. Estuaries 19, 740-750. doi: 10.2307/1352533

Kirk, J. (2010). Light and Photosynthesis in Aquatic Ecosystems, 3rd Edn. New York, NY: Cambridge University Press. doi: $10.1017 /$ CBO9781139168212

Kirk, J. T. O. (1976). Yellow substance (gelbstoff) and its contribution to the attenuation of photosynthetically active radiation in some inland and coastal south-eastern Australian waters. Mar. Freshw. Res. 27, 61-71. doi: 10.1071/MF9760061

Kirk, J. T. O. (1985). Effects of suspensoids (turbidity) on penetration of solar radiation in aquatic ecosystems. Hydrobiologia 125, 195-208.

Kleypas, J. A., Mcmanus, J. W., and Meñez, L. A. (1999). Environmental limits to coral reef development: where do we draw the line? Am. Zool. 39, 146-159. doi: $10.1093 / \mathrm{icb} / 39.1 .146$

Kramer, N., Tamir, R., Eyal, G., and Loya, Y. (2020). Coral morphology portrays the spatial distribution and population size-structure along a 5-100 $\mathrm{m}$ depth gradient. Front. Mar. Sci. 7:615. doi: 10.3389/fmars.2020.00615

Kuhl, M., Cohen, Y., Dalsgaard, T., Jorgensen, B. B., and Revsbech, N. P. (1995). Microenvironment and photosynthesis of zooxanthellae in scleractinian corals studied with microsensors for $\mathrm{O}_{2}, \mathrm{pH}$ and light. Mar. Ecol. Prog. Ser. 117, 159-172. doi: 10.3354/meps117159

Kuwahara, V., Nakajima, R., Othman, B., Kushairi, M., and Toda, T. (2010). Spatial variability of UVR attenuation and bio-optical factors in shallow coral-reef waters of Malaysia. Coral Reefs 29, 693-704. doi: 10.1007/s00338-010-0618-1

Lajeunesse, T. C., Parkinson, J. E., Gabrielson, P. W., Jeong, H. J., Reimer, J. D., Voolstra, C. R., et al. (2018). Systematic revision of Symbiodiniaceae highlights the antiquity and diversity of coral endosymbionts. Curr. Biol. 28, 2570-2580. doi: 10.1016/j.cub.2018.07.008

Lambrechts, J., Humphrey, C., Mckinna, L., Gourge, O., Fabricius, K. E., Mehta, A. J., et al. (2010). Importance of wave-induced bed liquefaction in the fine sediment budget of Cleveland Bay, Great Barrier Reef. Estuar. Coast. Shelf Sci. 89, 154-162. doi: 10.1016/j.ecss.2010.06.009

Larcombe, P., Costen, A., and Woolfe, K. J. (2001). The hydrodynamic and sedimentary setting of nearshore coral reefs, central Great Barrier Reef shelf, Australia: Paluma Shoals, a case study. Sedimentology 48, 811-835. doi: 10.1046/j.1365-3091.2001.00396.x

Larcombe, P., Ridd, P., Prytz, A., and Wilson, B. (1995). Factors controlling suspended sediment on inner-shelf coral reefs, Townsville, Australia. Coral Reefs 14, 163-171. doi: 10.1007/BF00367235

Larcombe, P., and Woolfe, K. J. (1999). Terrigenous sediments as influences upon Holocene nearshore coral reefs, central Great Barrier Reef, Australia. Aust. J. Earth Sci. 46, 141-154. 
Lee, K.-S., Park, S. R., and Kim, Y. K. (2007a). Effects of irradiance, temperature, and nutrients on growth dynamics of seagrasses: a review. J. Exp. Mar. Biol. Ecol. 350, 144-175. doi: 10.1016/j.jembe.2007.06.016

Lee, Z., Weidemann, A., Kindle, J., Arnone, R., Carder, K. L., and Davis, C. (2007b). Euphotic zone depth: its derivation and implication to ocean-color remote sensing. J. Geophysic. Res. Oceans 112:3802. doi: 10.1029/2006JC003802

Lesser, M., and Gorbunov, M. (2001). Diurnal and bathymetric changes in chlorophyll fluorescence yields of reef corals measured in situ with a fast repetition rate fluorometer. Mar. Ecol. Prog. Ser. 212, 69-77. doi: $10.3354 /$ meps 212069

Lesser, M. P. (2004). Experimental biology of coral reef ecosystems. J. Exp. Mar. Biol. Ecol. 300, 217-252. doi: 10.1016/j.jembe.2003.12.027

Lesser, M. P., Slattery, M., and Leichter, J. J. (2009). Ecology of mesophotic coral reefs. J. Exp. Mar. Biol. Ecol. 1, 1-8. doi: 10.1016/j.jembe.2009.05.009

Levy, O., Dubinsky, Z., and Achituv, Y. (2003). Photobehavior of stony corals: responses to light spectra and intensity. J. Exp. Biol. 206, 4041-4049. doi: $10.1242 /$ jeb.00622

Lichtenberg, M., Larkum, A. W. D., and Kühl, M. (2016). Photosynthetic acclimation of Symbiodinium in hospite depends on vertical position in the tissue of the Scleractinian coral Montastrea curta. Front. Microbiol. 7:230. doi: $10.3389 /$ fmicb. 2016.00230

Lou, J., and Ridd, P. V. (1996). Wave-current bottom shear stresses and sediment resuspension in Cleveland Bay, Australia. Coast. Eng. 29, 169-186. doi: 10.1016/S0378-3839(96)00023-3

Luter, H. M., Pineda, M.-C., Ricardo, G., Francis, D. S., Fisher, R., and Jones, R. (2021). Assessing the risk of light reduction from natural sediment resuspension events and dredging activities in an inshore turbid reef environment. Mar. Pollut. Bull. 170:112536. doi: 10.1016/j.marpolbul.2021.112536

Macdonald, R., Ridd, P., Whinney, J., Larcombe, P., and Neil, D. (2013). Towards environmental management of water turbidity within open coastal waters of the Great Barrier Reef. Mar. Pollut. Bull. 74, 82-94. doi: 10.1016/j.marpolbul.2013.07.026

Mapstone, B. D., Choat, J., Cumming, R., and Oxley, W. (1992). The Fringing Reefs of Magnetic Island: Benthic Biota and Sedimentation-A Baseline Study: A Report to the Great Barrier Reef Marine Park Authority. Research report No. 13. Great Barrier Reef Marine Park Authority, Townsville, QLD.

Maritorena, S., and Guillocheau, N. (1996). Optical properties of water and spectral light absorption by living and non-living particles and by yellow substances in coral reef waters of French Polynesia. Mar. Ecol. Prog. Ser. 131, 245-255. doi: $10.3354 /$ meps 131245

Mass, T., Kline, D. I., Roopin, M., Veal, C. J., Cohen, S., Iluz, D., et al. (2010). The spectral quality of light is a key driver of photosynthesis and photoadaptation in Stylophora pistillata colonies from different depths in the Red Sea. J. Exp. Biol. 213, 4084-4091. doi: 10.1242/jeb.039891

Mathews, E. J., Heap, A. D., and Woods, M. (2007). Inter-Reefal Seabed Sediments and Geomorphology of the Great Barrier Reef, A Spatial Analysis. (Geoscience Australia, Record 2007/09).

McDonald, J., Mcgee, J., Brent, K., and Burns, W. (2019). Governing geoengineering research for the Great Barrier Reef. Clim. Policy 19, 801-811. doi: 10.1080/14693062.2019.1592742

Mies, M., Francini-Filho, R. B., Zilberberg, C., Garrido, A. G., Longo, G. O., Laurentino, E., et al. (2020). South atlantic coral reefs are major global warming refugia and less susceptible to bleaching. Front. Mar. Sci. 7:514. doi: 10.3389/fmars.2020.00514

Mobley, C. D. (1994). Light and Water: Radiative Transfer in Natural Waters. San Diego, CA: Academic Press.

Mobley, C. D., Stramski, D., Paul Bissett, W., and Boss, E. (2004). Optical modeling of ocean waters: is the case 1-case 2 classification still useful? Oceanography 17:60. doi: 10.5670/oceanog.2004.48

Morel, A. (1978). Available, usable, and stored radiant energy in relation to marine photosynthesis. Deep Sea Res. 25, 673-688. doi: 10.1016/0146-6291(78)90623-9

Morel, A. (1988). Optical modeling of the upper ocean in relation to its biogenous matter content (case I waters). J. Geophys. Res. Oceans 93, 10749-10768. doi: 10.1029/JC093iC09p10749

Morel, A. (1991). Light and marine photosynthesis: a spectral model with geochemical and climatological implications. Prog. Oceanogr. 26, 263-306. doi: 10.1016/0079-6611(91)90004-6
Morel, A., and Antoine, D. (1994). Heating rate within the upper ocean in relation to its bio-optical state. J. Phys. Oceanogr. 24, 1652-1665.

Morel, A., Claustre, H., Antoine, D., and Gentili, B. (2007). Natural variability of bio-optical properties in Case 1 waters: attenuation and reflectance within the visible and near-UV spectral domains, as observed in South Pacific and Mediterranean waters. Biogeosciences 4, 913-925. doi: 10.5194/bg-4-913-2007

Morel, A., and Maritorena, S. (2001). Bio-optical properties of oceanic waters: a reappraisal. J. Geophys. Res. Oceans 106, 7163-7180. doi: 10.1029/2000JC000319

Morel, A., and Prieur, L. (1977). Analysis of variations in ocean color 1. Limnol. Oceanogr. 22, 709-722. doi: 10.4319/lo.1977.22.4.0709

Morgan, K. M., Moynihan, M. A., Sanwlani, N., and Switzer, A. D. (2020). Light limitation and depth-variable sedimentation drives vertical reef compression on turbid coral reefs. Front. Mar. Sci. 7:931. doi: 10.3389/fmars.2020.571256

Morgan, K. M., Perry, C. T., Johnson, J. A., and Smithers, S. G. (2017). Nearshore turbid-zone corals exhibit high bleaching tolerance on the great barrier reef following the 2016 ocean warming event. Front. Mar. Sci. 4:224. doi: $10.3389 /$ fmars.2017.00224

Morgan, K. M., Perry, C. T., Smithers, S. G., Johnson, J. A., and Daniell, J. J. (2016). Evidence of extensive reef development and high coral cover in nearshore environments: implications for understanding coral adaptation in turbid settings. Sci. Rep. 6:29616. doi: 10.1038/srep29616

Muir, P. R., Wallace, C. C., Done, T., and Aguirre, J. D. (2015). Limited scope for latitudinal extension of reef corals. Science 348, 1135-1138. doi: 10.1126/science.1259911

Muscatine, L. (1990). The role of symbiotic algae in carbon and energy flux in reef corals. Ecosyst. World 25, 75-87.

Nack, M., and Green, A. (1974). Influence of clouds, haze, and smog on the middle ultraviolet reaching the ground. Appl. Opt. 13, 2405-2415. doi: 10.1364/AO.13.002405

Niedzwiedzki, D. M., Jiang, J., Lo, C. S., and Blankenship, R. E. (2014). Spectroscopic properties of the Chlorophyll a-Chlorophyll c2-PeridininProtein-Complex (acpPC) from the coral symbiotic dinoflagellate Symbiodinium. Photosyn. Res. 120, 125-139. doi: 10.1007/s11120-013-9794-5

Orpin, A., and Ridd, P. (2012). Exposure of inshore corals to suspended sediments due to wave-resuspension and river plumes in the central Great Barrier Reef: a reappraisal. Cont. Shelf Res. 47, 55-67. doi: 10.1016/j.csr.2012.06.013

Orpin, A., Ridd, P., and Stewart, L. (1999). Assessment of the relative importance of major sediment transport mechanisms in the central Great Barrier Reef lagoon. Austr. J. Earth Sci. 46, 883-896. doi: 10.1046/j.1440-0952.1999.00751.x

Orpin, A., Ridd, P., Thomas, S., Anthony, K., Marshall, P., and Oliver, J. (2004). Natural turbidity variability and weather forecasts in risk management of anthropogenic sediment discharge near sensitive environments. Mar. Pollut. Bull. 49, 602-612. doi: 10.1016/j.marpolbul.2004.03.020

Otis, D. B., Carder, K. L., English, D. C., and Ivey, J. E. (2004). CDOM transport from the Bahamas Banks. Coral Reefs 23, 152-160. doi: 10.1007/s00338-003-0356-8

Passlow, V., Rogis, J., Hancock, A., Hemer, M., Glenn, K., and Habib, A. (2005). National Marine Sediments Database and Seafloor Characteristics Project. Final report prepared for the National Oceans Office, Hobart, TAS.

Pecenak, Z. K., Mejia, F. A., Kurtz, B., Evan, A., and Kleissl, J. (2016). Simulating irradiance enhancement dependence on cloud optical depth and solar zenith angle. Solar Energy 136, 675-681. doi: 10.1016/j.solener.2016.07.045

Perry, C., Smithers, S., Gulliver, P., and Browne, N. (2012). Evidence of very rapid reef accretion and reef growth under high turbidity and terrigenous sedimentation. Geology 40, 719-722. doi: 10.1130/G33261.1

Perry, C. T., and Larcombe, P. (2003). Marginal and non-reef-building coral environments. Coral Reefs 22, 427-432. doi: 10.1007/s00338-0030330-5

Petus, C., Devlin, M., Teixera Da Silva, E., Lewis, S., Waterhouse, J., Wenger, A., et al. (2018). Defining wet season water quality target concentrations for ecosystem conservation using empirical light attenuation models: a case study in the Great Barrier Reef (Australia). J. Environ. Manage. 213, 451-466. doi: 10.1016/j.jenvman.2018.02.028

Pfister, G., Mckenzie, R., Liley, J., Thomas, A., Forgan, B., and Long, C. N. (2003). Cloud coverage based on all-sky imaging and its impact on surface solar irradiance. J. Appl. Meteorol. Climatol. 42, 1421-1434. doi: 10.1175/1520-0450(2003)042andlt;1421:CCBOAIandgt;2.0.CO;2 
Polívka, T., Hiller, R. G., and Frank, H. A. (2007). Spectroscopy of the peridinin-chlorophyll- a protein: insight into light-harvesting strategy of marine algae. Arch. Biochem. Biophys. 458, 111-120. doi: 10.1016/j.abb.2006. 10.006

Poquita-Du, R. C., Quek, Z. B. R., Jain, S. S., Schmidt-Roach, S., Tun, K., Heery, E. C., et al. (2019). Last species standing: loss of Pocilloporidae corals associated with coastal urbanization in a tropical city state. Mar. Biodivers. 49, 1727-1741. doi: 10.1007/s12526-019-00939-x

Potts, D., and Jacobs, J. (2000). "Evolution of reef-building scleractinian corals in turbid environments: a paleo-ecological hypothesis," in Proceedings of the Ninth International Coral Reef Symposium (Bali), 249-254.

Preisendorfer, R. W., and Mobley, C. D. (1986). Albedos and glitter patterns of a wind-roughened sea surface. J. Physic. Oceanogr. 16, 1293-1316. doi: 10.1175/1520-0485(1986)016andlt;1293:AAGPOAandgt;2.0.CO;2

Prézelin, B., and Haxo, F. (1976). Purification and characterization of peridininchlorophyll a -proteins from the marine dinoflagellates Glenodinium sp. and Gonyaulax polyedra. Planta 128, 133-141. doi: 10.1007/BF00390314

Prézelin, B., Ley, A. C., and Haxo, F. (1976). Effects of growth irradiance on the photosynthetic action spectra of the marine dinoflagellate, Glenodinium sp. Planta 130, 251-256. doi: 10.1007/BF00387829

Prieur, L., and Sathyendranath, S. (1981). An optical classification of coastal and oceanic waters based on the specific spectral absorption curves of phytoplankton pigments, dissolved organic matter, and other particulate materials 1. Limnol. Oceanogr. 26, 671-689.

R Core Team (2020). R: A Language and Environment for Statistical Computing. R Foundation for Statistical Computing, Vienna. Available online at: https:// www.R-project.org/

Reichelt, A. J., and Jones, G. B. (1994). Trace metals as tracers of dredging activity in Cleveland Bay-field and laboratory studies. Mar. Freshw. Res. 45, 1237-1257. doi: 10.1071/MF9941237

Robinson, N. (1966). Solar Radiation. New York, NY: Elsevier.

Roth, M. S. (2014). The engine of the reef: photobiology of the coral-algal symbiosis. Front. Microbiol. 5:422. doi: 10.3389/fmicb.2014.00422

Rue, H., Martino, S., and Chopin, N. (2009). Approximate bayesian inference for latent gaussian models by using integrated nested laplace approximations. J. $R$. Stat. Soc. Ser. B 71, 319-392. doi: 10.1111/j.1467-9868.2008.00700.x

Salih, A., Larkum, A., Cox, G., Kühl, M., and Hoegh-Guldberg, O. (2000). Fluorescent pigments in corals are photoprotective. Nature 408, 850-853. doi: 10.1038/35048564

Schlichter, D., and Fricke, H. W. (1991). Mechanisms of amplification of photosynthetically active radiation in the symbiotic deep-water coral Leptoseris fragilis. Hydrobiologia 216, 389-394. doi: 10.1007/BF00026491

Schlichter, D., Fricke, H. W., and Weber, W. (1986). Light harvesting by wavelength transformation in a symbiotic coral of the Red Sea twilight zone. Mar. Biol. 91, 403-407. doi: 10.1007/BF00428634

Schuhmacher, H., and Zibrowius, H. (1985). What is hermatypic? Coral Reefs 4, 1-9. doi: 10.1007/BF00302198

Scott, B. D., and Jitts, H. R. (1977). Photosynthesis of phytoplankton and zooxanthellae on a coral reef. Mar. Biol. 41, 307-315. doi: 10.1007/BF003 89097

Sherman, D. M., and Waite, T. D. (1985). Electronic spectra of Fe3+ oxides and oxide hydroxides in the near IR to near UV. Am. Mineral. 70, 1262-1269.

Shi, K., Li, Y., Li, L., and Lu, H. (2013). Absorption characteristics of optically complex inland waters: implications for water optical classification. J. Geophys. Res. Biogeosci. 118, 860-874. doi: 10.1002/jgrg.20071

Slivkoff, M. (2014). Ocean Colour Remote Sensing of the Great Barrier Reef Waters [Ph.D. thesis], School of Science, Department of Imaging \& Applied Physics, Bentley, WA: Curtin University.

Smith, E. G., D'angelo, C., Sharon, Y., Tchernov, D., and Wiedenmann, J. (2017). Acclimatization of symbiotic corals to mesophotic light environments through wavelength transformation by fluorescent protein pigments. Proc. R. Soc. B Biol. Sci. 284:20170320. doi: 10.1098/rspb.2017.0320

Smith, R. C., and Baker, K. S. (1978). Optical classification of natural waters 1. Limnol. Oceanogr. 23, 260-267. doi: 10.4319/lo.1978.23.2.0260

Smith, R. C., and Baker, K. S. (1981). Optical properties of the clearest natural waters (200-800 nm). Appl. Opt. 20:177. doi: 10.1364/AO.20.000177

Song, P.-S., Koka, P., Prezelin, B. B., and Haxo, F. T. (1976). Molecular topology of the photosynthetic light-harvesting pigment complex, peridinin-chlorophyll a-protein, from marine dinoflagellates. Biochemistry 15, 4422-4427. doi: 10.1021/bi00665a012

Spencer Davies, P. (1989). Short-term growth measurements of corals using an accurate buoyant weighing technique. Mar. Biol. 101, 389-395. doi: $10.1007 / \mathrm{BF} 00428135$

Stimson, J., and Kinzie, R. A. (1991). The temporal release of zooxanthellae from the reef coral Pocillopora damicornis (Linnaeus) under nitrogenenrichment and control conditions. J. Exp. Mar. Biol. Ecol. 153, 63-74. doi: 10.1016/S0022-0981(05)80006-1

Stramski, D., Babin, M., and Wozniak, S. B. (2007). Variations in the optical properties of terrigenous mineral-rich particulate matter suspended in seawater. Limnol. Oceanogr. 52, 2418-2433. doi: 10.4319/lo.2007.52.6.2418

Sully, S., and Van Woesik, R. (2020). Turbid reefs moderate coral bleaching under climate-related temperature stress. Glob. Change Biol. 26, 1367-1373. doi: $10.1111 / \mathrm{gcb} .14948$

Sundarabalan, B., Shanmugam, P., and Ahn, Y.-H. (2016). Modeling the underwater light field fluctuations in coastal oceanic waters: validation with experimental data. Ocean Sci. J. 51, 67-86. doi: 10.1007/s12601-016-0007-y

Szabó, M., Wangpraseurt, D., Tamburic, B., Larkum, A. W., Schreiber, U., Suggett, D. J., et al. (2014). Effective light absorption and absolute electron transport rates in the coral Pocillopora damicornis. Plant Physiol. Biochem. 83, 159-167. doi: 10.1016/j.plaphy.2014.07.015

Thompson, A., Costello, P., Davidson, J., Logan, M., Coleman, G., and Gunn, K. (2018). Marine Monitoring Program. Annual Report for Inshore Coral Reef Monitoring: 2016 - 2017. Great Barrier Reef Marine Park Authority, Townsville, QLD.

Van Duin, E. H., Blom, G., Los, F. J., Maffione, R., Zimmerman, R., Cerco, C. F., et al. (2001). Modeling underwater light climate in relation to sedimentation, resuspension, water quality and autotrophic growth. Hydrobiologia 444, 25-42. doi: 10.1023/A:1017512614680

Van Woesik, R., Houk, P., Isechal, A. L., Idechong, J. W., Victor, S., and Golbuu, Y. (2012). Climate-change refugia in the sheltered bays of Palau: analogs of future reefs. Ecol. Evol. 2, 2474-2484. doi: 10.1002/ece3.363

Wangpraseurt, D., Larkum, A. W., Franklin, J., Szab,ó, M., Ralph, P. J., and Kühl, M. (2014a). Lateral light transfer ensures efficient resource distribution in symbiont-bearing corals. J. Exp. Biol. 217, 489-498. doi: 10.1242/jeb.091116

Wangpraseurt, D., Larkum, A. W., Ralph, P. J., and Kühl, M. (2012). Light gradients and optical microniches in coral tissues. Front. Microbiol. 3:316. doi: 10.3389/fmicb.2012.00316

Wangpraseurt, D., Polerecky, L., Larkum, A. W., Ralph, P. J., Nielsen, D. A., Pernice, M., et al. (2014b). The in situ light microenvironment. Corals 59, 917-926. doi: 10.4319/lo.2014.59.3.0917

Wangpraseurt, D., Tamburic, B., Szabó, M., Suggett, D., Ralph, P. J., and Kühl, M. (2014c). Spectral Effects on Symbiodinium photobiology studied with a programmable light engine. PLOS ONE 9:e112809. doi: 10.1371/journal.pone.0112809

Waterhouse, J., Gruber, R., Logan, M., Petus, C., Howley, C., Lewis, S., et al. (2021). Marine Monitoring Program: Annual Report for Inshore Water Quality Monitoring 2019-20. Report for the Great Barrier Reef Marine Park Authority, Great Barrier Reef Marine Park Authority, Townsville, QLD.

Webb, J. R., Santos, I. R., Maher, D. T., Tait, D. R., Cyronak, T., SadatNoori, M., et al. (2019). Groundwater as a source of dissolved organic matter to coastal waters: insights from radon and CDOM observations in 12 shallow coastal systems. Limnol. Oceanogr. 64, 182-196. doi: 10.1002/lno. 11028

Wellington, G. (1982). An experimental analysis of the effects of light and zooplankton on coral zonation. Oecologia 52, 311-320.

Whinney, K. J., Jones, R., Duckworth, A., and Ridd, P. (2017). Continuous in situ monitoring of sediment deposition in shallow benthic environments. Coral Reefs 36, 521-533. doi: 10.1007/s00338-016-1536-7

Woolfe, K., and Larcombe, P. (1998). "Terrigenous sediment accumulation as a regional control on the distribution of reef carbonates," in Reefs and Carbonate Platforms in the Pacific and Indian Oceans, eds G. Camoin and P. Davies (International Association of Sedimentologists (IAS) Special Publication) 25, 295-310. doi: 10.1002/9781444304879.ch16

Woolfe, K. J., and Larcombe, P. (1999). Terrigenous sedimentation and coral reef growth: a conceptual framework. Mar. Geol. 155, 331-345. doi: 10.1016/S0025-3227(98)00131-5 
Wozniak, B., and Dera, J. (2007). Light Absorption in Sea Water. New York, NY: Springer.

Wyman, K., Dubinsky, Z., Porter, J., and Falkowski, P. (1987). Light absorption and utilization among hermatypic corals: a study in Jamaica, West Indies. Mar. Biol. 96, 283-292. doi: 10.1007/BF00427028

Yentsch, C., Yentsch, C., Cullen, J., Lapointe, B., Phinney, D., and Yentsch, S. (2002). Sunlight and water transparency: cornerstones in coral research. J. Exp. Mar. Biol. Ecol. 268, 171-183. doi: 10.1016/S0022-0981(01) 00379-3

Yordanov, G. H., Midtgård, O.-M., Saetre, T. O., Nielsen, H. K., and Norum, L. E. (2013). Overirradiance (cloud enhancement) events at high latitudes. IEEE J. Photovoltaics 3, 271-277. doi: 10.1109/JPHOTOV.2012.22 13581

Yordanov, G. H., Saetre, T. O., and Midtgård, O.-M. (2015). Extreme overirradiance events in Norway: 1.6 suns measured close to $60 \mathrm{~N}$. Solar Energy 115, 68-73. doi: 10.1016/j.solener.2015.02.020

Ziegler, M., Roder, C. M., Büchel, C., and Voolstra, C. R. (2014). Limits to physiological plasticity of the coral Pocillopora verrucosa from the central Red Sea. Coral Reefs 33, 1115-1129. doi: 10.1007/s00338-014-1192-8

Zweifler, A., O'leary, M., Morgan, K., and Browne, N. K. (2021). Turbid coral reefs: past, present and future-a review. Diversity 13:251. doi: 10.3390/d13 060251
Conflict of Interest: WK and MS were employed by company In-situ Marine Optics.

The remaining authors declare that the research was conducted in the absence of any commercial or financial relationships that could be construed as a potential conflict of interest.

Publisher's Note: All claims expressed in this article are solely those of the authors and do not necessarily represent those of their affiliated organizations, or those of the publisher, the editors and the reviewers. Any product that may be evaluated in this article, or claim that may be made by its manufacturer, is not guaranteed or endorsed by the publisher.

Copyright (c) 2021 Jones, Pineda, Luter, Fisher, Francis, Klonowski and Slivkoff. This is an open-access article distributed under the terms of the Creative Commons Attribution License (CC BY). The use, distribution or reproduction in other forums is permitted, provided the original author(s) and the copyright owner(s) are credited and that the original publication in this journal is cited, in accordance with accepted academic practice. No use, distribution or reproduction is permitted which does not comply with these terms. 